\title{
CACERÍA DE GUANACOS EN EL CHACO ÁRIDO (CÓRDOBA, ARGENTINA): UNA MIRADA DESDE LA ZOOARQUEOLOGÍA
}

\author{
GUANACO HUNTING IN THE ARID CHACO (CÓRDOBA, ARGENTINA): A \\ ZOOARCHAEOLOGICAL PERSPECTIVE
}

\author{
Thiago Costa1 ${ }^{1}$ María Paula Weihmüller ${ }^{1,2}$ y Jessica Manzano-García ${ }^{1,2}$
}

\begin{abstract}
Se presentan análisis zooarqueológicos de una colección moderna de 24 guanacos (Lama guanicoe), producto de la cacería, procesamiento, consumo y descarte de los animales en un campo del noroeste de la Provincia de Córdoba, Argentina. A lo anterior, se suma información obtenida a través de entrevistas semiestructuradas $(n=50)$, en ocasiones con la participación de dos o tres interlocutores, abiertas, en profundidad ( $\mathrm{n}=16$ ), y observaciones participantes con pobladores locales $(\mathrm{N}=8)$, con el objetivo de aportar a la comprensión de las relaciones humano-guanacos desde una arqueología del pasado contemporáneo (fines del siglo XX hasta la actualidad). Nuestros resultados ponen en evidencia cambios y continuidades respecto a las prácticas de cacería, procesamiento y el aprovechamiento de estos ungulados. Además, el valor simbólico y medicinal de la especie para la comunidad local es discutido a la luz de los resultados que se presentan. Por último, se destaca que los cambios socioeconómicos y ecológicos característicos del Antropoceno han puesto al guanaco en peligro de extinción a nivel provincial. De esta manera, se destaca la importancia de realizar una arqueología del pasado contemporáneo que contribuya a la conservación biocultural en el área.
\end{abstract}

Palabras claves: arqueología, zooarqueología, guanaco, Antropoceno, Córdoba.

We present a zooarchaeological analysis of a modern collection of 24 guanacos (Lama guanicoe), a product of the hunting, processing, consumption and disposal of the animals in a field located in the northwest of the province of Córdoba, Argentina. To the previous analyses, we add information obtained through semi-structured interviews $(n=50)$, sometimes with the participation of two or three interlocutors, open and in-depth $(n=16)$, and participant observation with local residents $(N=8)$, in an attempt to contribute to the understanding of human-guanaco relations through an archaeology of the contemporary past (late 20th century to present). Our results show changes and continuities regarding the hunting, processing and use of these ungulates. In light of our results, we also discuss the symbolic and medicinal value of the species for the local community. Finally, we draw attention to how the socioeconomic and ecological changes associated with the Anthropocene have endangered guanacos at a provincial scale. Thus, we underscore the importance of addressing an archaeology of the contemporary era which contributes to biocultural conservation in the area.

Key words: Archaeology, zooarchaeology, guanaco, Anthropocene, Córdoba.

Este trabajo pretende ser un aporte reflexivo y políticamente posicionado, orientado al estudio de las interacciones entre humanos y guanacos, tanto actuales como del pasado reciente. Para ello, analizaremos una colección osteológica moderna de estos animales, producida por actividades de caza, procesamiento y descarte que tuvieron lugar en un campo emplazado entre las localidades de Piedrita Blanca y El Chacho, al noroeste de la Provincia de Córdoba, Argentina. Los resultados del análisis osteofaunístico serán discutidos e interpretados a la luz de información de corte etnoarqueológico, buscando poner nuestra pesquisa en diálogo con las propuestas de una arqueología del pasado contemporáneo (Buchli y Lucas 2001; González-Ruibal 2019; Harrison y Breithoff 2017, entre otros).

El enfoque que desarrollaremos a lo largo de este trabajo no es precisamente novedoso; de hecho, sus raíces pueden rastrearse hasta los estudios de la cultura material contemporánea iniciados a fines de la década de 1970 (Gould 1978; Gould y Schiffer 1981; Rathje 1979; Shanks y Tilley 1987). Dichos

1 Instituto de Antropología de Córdoba, Museo de Antropología, Facultad de Filosofía y Humanidades, Universidad Nacional de Córdoba, Córdoba, Argentina. thiagosilva@ffyh.unc.edu.ar; mpweihmuller@conicet.gov.ar; jmanzanog17@gmail.com 2 CONICET - Consejo Nacional de Investigaciones Científicas y Técnicas, Buenos Aires, Argentina. 
trabajos, de enfoque actualístico, se consolidaron a la par de otra línea importante para el desarrollo de nuestra metodología: la etnoarqueología (Adams 1983; Binford 1978, 1981; David y Kramer 2001; Hodder 1982). Esta última surgió de la necesidad de generar material etnográfico que fuera útil para la interpretación de contextos arqueológicos (Longacre 1978, para una revisión de estas primeras aproximaciones), aunque el profuso desarrollo de esta línea ha demostrado su utilidad más allá de las analogías (González-Ruibal 2017).

En este contexto de creciente especialización surge la etnozooarqueología, subdisciplina preocupada por un aspecto particular de la vida humana, esto es, las interacciones materiales entre humanos y animales (Albarella y Trentacoste 2011; Broderick 2016). En Argentina diversos desarrollos podrían enmarcarse en esta línea (Politis y Martínez 1996; Politis y Saunders 2002; Yacobaccio et al. 1998). Entre los trabajos más recientes, se cuentan la investigación sobre nutrieros y cazadores de coipo en la Pampa húmeda argentina (Escosteguy 2011, 2014), el trabajo con puesteros realizado en el sur mendocino (Giardina 2010; Otaola et al. 2016), o la investigación etnográfica con pastores de ganado caprino realizada por Gasco et al. (2015).

En este sentido, concordamos con Majewski y Schiffer (2001) cuando afirman que los límites entre diferentes ramas de la arqueología son difusos. De todas formas, creemos que estos aportes son útiles no solo como generadores de información relevante para la discusión e interpretación del registro óseo faunístico -la cultura material que nos hemos propuesto analizar-, sino también como estrategias de investigación que permiten combinar diversos abordajes (p.ej., etnoarqueológicos, etnohistóricos, zooarqueológicos) para tratar una problemática específica (Albarella 2011).

A fin de cuentas, lo que todas las arqueologías tienen en común es una preocupación por recuperar vestigios materiales, analizando las marcas resultantes de las interacciones entre las personas y dichos restos; en eso estamos de acuerdo. Sin embargo, en un momento en el que el mundo se encuentra sometido a los embates inusitados de la acción humana -el Antropoceno-, concordamos con Laurent Olivier (2019:30) cuando afirma que:

The province of archaeology is the here and now; what we study is what the present does to the world. And it is the advent of the Anthropocene that has taught us this. We can thus use presentism as a weapon with which to combat presentism itself, or, at least, what brought it on. Seen in this perspective, archaeology's lone vocation is that of resistance. (...) It is another way of conceiving the world and a consciousness of the fragility of things, beings and places. The work to be done is enormous.

Si bien habrá quienes consideren que semejante planteo no es más que una utopía, tenerlo de horizonte nos ha ayudado a marcar el paso de nuestro trabajo que, mediado por el interés sobre el conocimiento de las prácticas cinegéticas actuales, pretende reflexionar crítica y políticamente sobre las mismas ${ }^{1}$. En este sentido, la mirada multitemporal de la arqueología adquiere particular importancia para explorar la relación entre humanos y guanacos en el marco de la "gran aceleración" del Antropoceno (Olivier 2019), atendiendo a sus cambios, sus rupturas y sus continuidades.

\section{Área de Estudio}

\section{Caracterización socioambiental}

El área de estudio (Figura 1) se sitúa en la región central de Argentina, en el extremo sur del Bolsón de las Salinas Grandes, una vasta depresión prácticamente rodeada por sierras que ocupa el oeste y extremo noroeste de la Provincia de Córdoba, extendiéndose también sobre el territorio de las provincias vecinas de San Luis, La Rioja, Catamarca y Santiago del Estero (Carignano et al. 2014). Las sierras actúan allí como barreras que restringen fuertemente las precipitaciones, lo que le confiere especiales características ambientales a esta subregión (Torrella y Adámoli 2005). A tono con las particularidades de una región semiárida, el clima es templado, con temperaturas medias de 25 ${ }^{\circ} \mathrm{C}$ en verano y $12{ }^{\circ} \mathrm{C}$ en invierno y precipitaciones principalmente concentradas en los meses cálidos.

En términos fitogeográficos, el área pertenece a la ecorregión del Gran Chaco, uno de los mayores ecosistemas de Sudamérica y uno de los ambientes de bosque seco más extenso a nivel mundial (Cabido et al. 2018). Particularmente, el Chaco Árido -la subregión donde se emplaza nuestro estudio- ha sido clasificado como un área de bosque de Aspidosperma quebracho-blanco y Prosopis nigra que está siendo rápida y preocupantemente desplazado por matorrales 


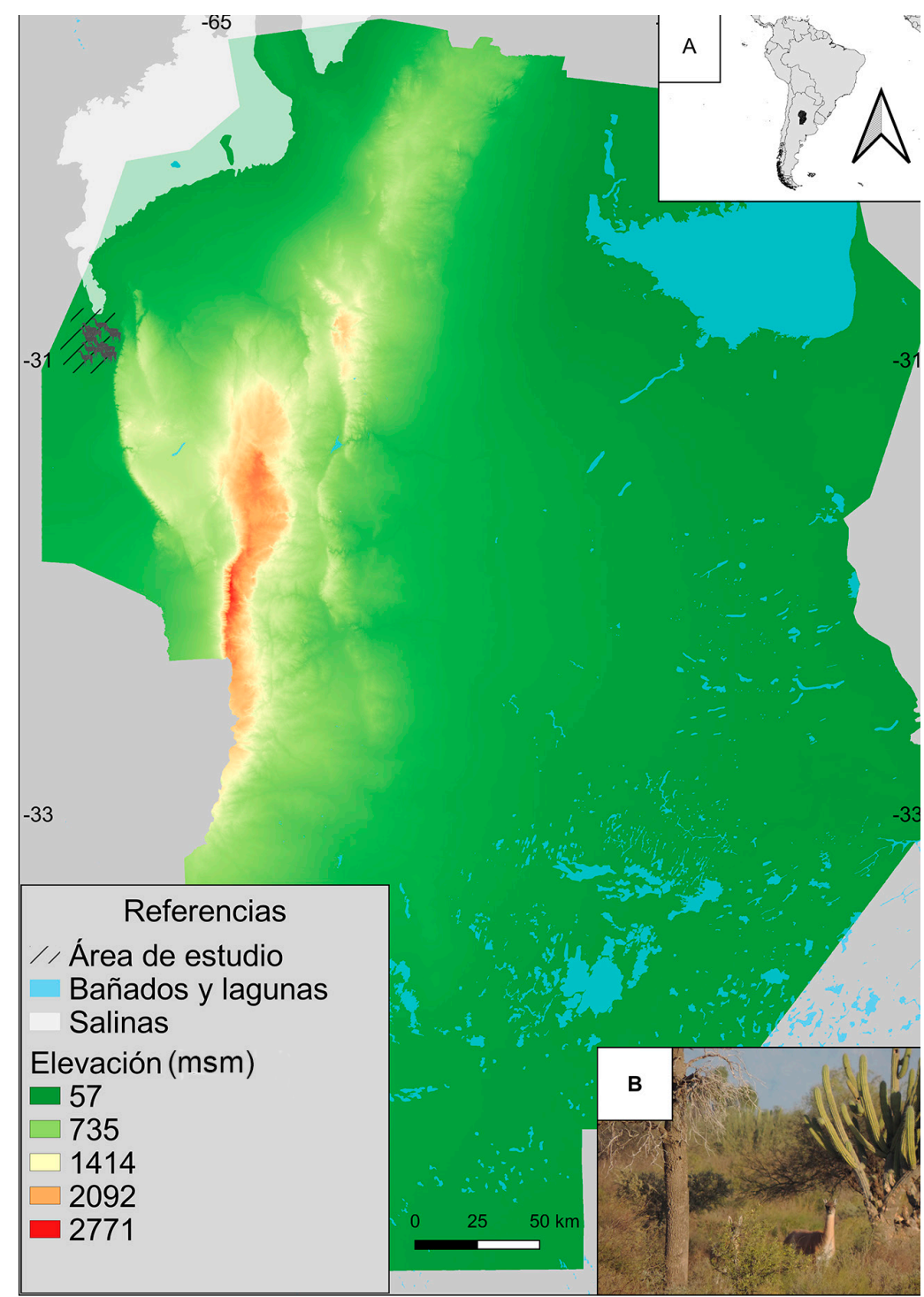

Figura 1. Área de estudio, Provincia de Córdoba enfatizando el borde sur de las Salinas Grandes; (A) localización de la Argentina y Provincia de Córdoba (en blanco) en Sudamérica; (B) guanaco en el área de estudio.

Study area, Córdoba province emphasizing the southern edge of the Salinas Grandes. (A) Location of Argentina and Córdoba province (in white) in South America. (B) Guanaco in the study area.

y paisajes antropizados (Zak y Cabido 2002). Por otra parte, zoogeográficamente, el área ha sido englobada dentro del Dominio Central o Subandino (Ringuelet 1961). No obstante, la diversidad y distribución faunística se han visto seriamente afectadas por los cambios acaecidos durante el Antropoceno (Dirzo et al. 2014), y el guanaco no ha sido la excepción. Aunque en el pasado reciente estos camélidos tuvieron una amplia distribución en la región, evocada en topónimos de ciertos parajes de la provincia donde actualmente la especie está extinta (Manzano-García et al. 2019), como Guanaco Muerto o El Guanaco, en la actualidad se encuentran reducidos a una pequeña población relictual en el noroeste de la provincia (Costa y Barri 2018) (Figura 1).

A nivel geopolítico, el área en donde se realizaron las entrevistas se encuentra entre los departamentos Minas y Cruz del Eje de la Provincia de Córdoba ${ }^{2}$, 
ambos compuestos predominantemente por población rural de acuerdo a los datos relevados por el Censo Nacional de Población (Instituto Nacional de Estadísticas y Censos [INDEC] 2010). El departamento Minas, donde se llevaron a cabo la mayor parte de las entrevistas, está caracterizado por viviendas dispersas $(51 \%)$, una predominancia de varones $(6,1$ por cada mujer) y una edad media de 34 años entre ambos sexos (Dirección General de Estadística y Censos de la Provincia de Córdoba [DGEC] 2017).

Por otra parte, resulta interesante mencionar que entre las décadas de 1980 y 1990, muchos de los varones del área se dedicaron a la extracción de leña, especialmente de quebracho colorado (Schinopsis lorentzii) que servía para alimentar los hornos de mineras -no en vano el nombre del departamento- o para la producción de carbón (para un proceso similar en Santiago del Estero, ver Bilbao 1964-65; Dargoltz 1991; para los llanos de La Rioja, Natenzon y Olivera 1994). Dicha actividad demandaba largos periodos en el monte, en campamentos comúnmente conocidos como obrajes, donde la caza habría sido fundamental para la obtención de carne ${ }^{3}$, en ocasiones como actividad económica complementaria y en otras para la subsistencia misma. Este particular contexto histórico local ha hecho de esta práctica parte de la trayectoria de vida de varios de nuestros interlocutores (Morello et al. 2005; Manzano García et al. 2019; Tamburini y Cáceres 2017). No obstante, desde finales de la década de 1980, la caza de fauna silvestre está regulada por legislación nacional y provincial ${ }^{4}$, asunto no menor que retomaremos más adelante.

\section{El Cementerio Ferrarini}

El sitio donde fue recolectada la mayor parte de la muestra ósea de Lama guanicoe estudiada se encuentra al interior de un campo privado ubicado entre Piedrita Blanca y El Chacho, dos pequeñas localidades rurales del noroeste cordobés. El campo - 18.000 ha- colinda al este con la Reserva Arqueológica de Guasapampa y hacia el sur y suroeste con el recientemente creado Parque Nacional Traslasierra, dos grandes áreas protegidas por la legislación nacional. Durante la época del obraje, este campo fue arrendado para tal fin y posteriormente destinado a la ganadería bovina, actividad que continúa desarrollándose en la actualidad.

A $2 \mathrm{~km}$ del puesto se encuentra el Cementerio Ferrarini, denominado así en virtud de la enorme acumulación de huesos con distintos grados de preservación de especies tanto nativas (p.ej., Rhea americana, Lama guanicoe, Pecari tajacu) -producto de la cacería ilegal- como introducidas (p.ej., Bos taurus, Equus sp.), que allí fueron encontrados. El sitio se destaca en el paisaje por la presencia de un claro alrededor de un algarrobo (Prosopis nigra), comúnmente llamado "el árbol" en el Chaco Árido (Bilbao 1964-1965; Gardenal Crivisqui 2018; ManzanoGarcía 2019). Allí, en un área de aproximadamente $200 \mathrm{~m}^{2}$, se encuentran distribuidos los huesos, en su mayoría superficialmente, aunque también se observaron especímenes semienterrados. La mayor concentración de huesos se encuentra en un radio de 15 m alrededor del árbol, en una superposición de animales que dificulta la diferenciación de individuos en la mayoría de los casos.

Cabe destacar que parte de la colección recuperada en este sitio fue estudiada por Costa y Barri (2018) con el objetivo de aplicar técnicas zooarqueológicas (p.ej., osteometría, estimación de edad y determinación de sexo) para caracterizar a esta población de guanacos chaqueños particularmente poco estudiada y aportar información relevante para su conservación.

\section{Metodología}

Dadas las posibilidades que se habilitan al poner en práctica una arqueología del mundo contemporáneo -inasequibles en otros contextos-, en este trabajo buscamos combinar dos vías analíticas complementarias que permitieron abordar la problemática desde distintos frentes. Por un lado, realizamos el análisis zooarqueológico de una colección osteológica moderna de Lama guanicoe (23 individuos) producto de actividades de cacería que tuvieron lugar en el campo. La recolección fue superficial y contó con la colaboración de algunos de nuestros interlocutores. En esta instancia, entre los años 2015 y 2019, priorizamos recuperar exhaustivamente los restos de guanacos y fauna endémica, evitando recolectar restos de fauna introducida que habían sido descartados en el mismo sitio $^{5}$. Cabe destacar que la recolección cubrió el área total del sitio y la identificación de los restos fue facilitada por el bajo grado de fragmentación de los elementos.

Por otro lado, en el año 2017, se incorporó a la muestra una carcasa parcialmente completa de un individuo cría (F1) que fue encontrado enredado y gravemente herido en uno de los alambrados que dividen los campos. Este último fue procesado para consumo de carne por dos de los entrevistados que posteriormente nos entregaron los restos de la carcasa. 


\section{Análisis zooarqueológicos}

Sobre ese conjunto llevamos a cabo análisis cuantitativos -i.e. cálculo de NISP (Grayson 1984), MNE, MNI (Lyman 1994), MAU y MAU\% (Binford 1978)- y cualitativos para el registro de alteraciones tafonómicas como la meteorización (Behrensmeyer 1978), morfología y estado de las fracturas (Villa y Mahieu 1991) y modificaciones causadas por carnívoros (Massigoge et al. 2014) y roedores (Fernández-Jalvo y Andrews 2016), entre otras modificaciones de la superficie cortical del hueso. En este trabajo, el foco estará puesto en las modificaciones de origen antrópico, es decir, las marcas de procesamiento. Para ello seguimos los lineamientos propuestos por otros autores (Binford 1981; Lupo 2009), identificando como marcas de corte aquellas huellas restringidas a la superficie cortical del hueso, generalmente largas ya que son el resultado de cortes con instrumentos metálicos a través del tejido (sensu Binford 1981:105), pudiendo aparecer aisladas o como líneas paralelas. Por su parte, los aserrados -i.e. cortes que atraviesan el hueso creando una fractura plana- fueron registrados diferencialmente. El relevamiento de cortes y aserrados fue realizado con la ayuda de una lupa de mano (5x) y lámpara con lupa de mesa (Full Energy RT205), los datos de su ubicación y orientación fueron volcados en plantillas ilustrativas para cada elemento utilizando el programa QGIS Desktop 3.8.1 (Abe et al. 2002; Izeta 2004; Nilssen 2000). Asimismo, el MAU\% fue correlacionado con los valores de densidad mineral ósea de Stahl (1999) mediante el coeficiente de correlación de Spearman utilizando el software Past3. Siguiendo las recomendaciones de Gutiérrez et al. (2010), esta correlación se realizó únicamente para el subconjunto de adultos (77\% de la muestra).

Por otra parte, elaboramos un perfil etario y sexual de la colección -presentado anteriormente de manera parcial (Costa y Barri 2018)- basado en el cronograma de erupción, desarrollo y desgaste dentario de los maxilares propuesto por Kaufmann (2009), complementando con las mandíbulas para precisar mejor la estimación solo en aquellos casos en los que se tenía la certeza de que ambos elementos pertenecían a un mismo animal. En cuanto a la determinación del sexo, utilizamos el índice de caninos propuesto por Raedeke (1979) y adaptado por Lefèvre et al. (2003) para aquellos casos en los que los caninos se encontraban ausentes, ambos aplicables unicamente a individuos adultos.

\section{Entrevistas y observación participante}

Más allá del análisis óseo, hemos buscado abordar la problemática incorporando la perspectiva de los pobladores locales, es decir, remitiéndonos al conocimiento local sobre la cacería y el aprovechamiento de los guanacos por parte de la comunidad, tanto en el pasado reciente como en la actualidad. Para aproximarnos a los pobladores locales, se recurrió a muestreos en bola de nieve y muestreo intencional de informantes claves (MartínCrespo y Salamanca-Castro 2007). La información se obtuvo por medio de entrevistas semiestructuradas, entrevistas abiertas, extensas y en profundidad, y observación participante.

Las entrevistas semiestructuradas $(\mathrm{N}=50)$ realizadas desde el inicio del trabajo de campo permitieron con flexibilidad el uso de tópicos previamente conocidos y otros que fueron redefinidos a través del desarrollo del estudio, adecuándose a las inquietudes durante la investigación y de acuerdo al análisis del material faunístico. Se trabajó con modelos adaptados de entrevistas generadas y aplicadas en temáticas afines (Manzano-García et al. 2019). Las entrevistas abiertas, extensas y en profundidad $(\mathrm{N}=16)$ lograron establecer diálogos libres entre los investigadores y los entrevistados; construyéndose un corpus de narrativas, información etnográfica y estudios de caso (Guber 2005). Se dio apertura al discurso a partir de preguntas grand tour, según la propuesta de Guber (2001), efectuándose interrogantes de ámbitos amplios (p.ej., ¿cuáles son las actividades laborales en el lugar?, ¿cómo se vive en el lugar?) para el reconocimiento y relevamiento inicial en la zona. El tamaño de muestra siguió el criterio de saturación de información, evitando la redundancia y optimizando los tiempos de trabajo. La observación participante $(\mathrm{N}=8)$ constó del primer contacto concreto e interactivo con las áreas de estudio (configuración espacio-temporal) y los grupos culturales con los que se trabajó y se mantuvo durante las salidas al campo (Dos Santos Rodríguez 2009), indagando específicamente sobre conocimiento, técnicas y prácticas de caza.

Las personas entrevistadas fueron adultos entre los 18 y 92 años de edad, con un promedio de edad de 57 años. Se caracterizan por ser en su mayoría actores sociales nativos con un perfil de subsistencia, generalmente varones debido a la temática estudiada -tradicionalmente asociada a actividades masculinas en el área de estudio- y las redes sociales habilitadas por nuestros colaboradores, cuya identidad elegimos 
resguardar haciendo uso únicamente de sus iniciales, por cuestiones de ética y seguridad dado lo delicado del tema tratado en términos legales, así como una descripción básica de sus actividades socioproductivas presentadas en la Tabla Suplementaria 1. Asimismo, siguiendo la propuesta de González-Ruibal (2019), se consideró la información histórica disponible sobre la cacería de guanacos a nivel regional, frente al desafío de poner en práctica una arqueología del mundo contemporáneo, es decir, que tenga en cuenta la materialidad en su multitemporalidad, las experiencias alternativas de las historias locales, y que sea crítica y políticamente cargada.

\section{Resultados y Discusión}

Los resultados, tanto del análisis sobre los restos óseos como de la información oral recopilada durante las estadías en el campo, serán presentados y discutidos de manera intercalada, con el fin de generar un cuerpo de información más sólido y coherente. Por otro lado, complementar los distintos frentes nos permite contrastar lo dicho con aquello que es hecho de manera inconsciente y no necesariamente verbalizado (González-Ruibal 2017).

\section{La cacería en la región: historia reciente y etnoarqueología}

Para empezar, es necesario que retomemos algunos detalles sobre la cacería y quienes la practicaban. De acuerdo a la información brindada por nuestros entrevistados, el Cementerio Ferrarini es producto de distintos eventos cinegéticos efectuados en el campo entre mediados de los años 1990 y 2013, año en que el actual encargado del campo (P.Q.) comenzó a trabajar. Durante la mayor parte de ese periodo, el campo estuvo a cargo de J.Z., ya fallecido, mientras que tan solo entre 2010 y 2013 el mando estuvo en manos de F.P. Ese puesto implica, principalmente, estar a cargo del cuidado del ganado vacuno y, por consiguiente, de la provisión de agua y alimento para los animales, el mantenimiento de los caminos y alambrados (un peligroso obstáculo para los guanacos), entre otras faenas.

De acuerdo a algunos de nuestros entrevistados, ambos solían cazar acompañados por otras personas (p.ej., J.C.), ya que "los cazadores siempre andan de a tres o cuatro" (N.Q.). Según nos cuenta B.Z., quien entonces convivía con J.Z. en el campo, "los patrones querían deshacerse de todo lo que era el burro y el guanaco, porque le comían el pasto" (información corroborada por N.P., quien también trabajó en el campo). J.Z. "les había cazado mucho, pero eran muchos en aquel entonces", nos relata B.Z. Este último fragmento de la entrevista con B.Z. trae a colación la alarmante disminución de la población de guanacos que habita el área en los últimos años, un dato que se repite en todas nuestras entrevistas. Por otra parte, un análisis del discurso nos sugiere que la actividad cinegética desarrollada durante aquellos años no estaba exclusivamente ligada a la subsistencia, sino que tenía otros fines incentivados por "los patrones", esto es, la "extinción" de los guanacos en el campo (B.Z., N.P.).

Con respecto a la experiencia de trabajo en compañía de F.P. -recordada de manera negativa por nuestro interlocutor-, P.Q. relata que, en ocasiones, al llegar al puesto luego de un periodo no laboral, "encontraba yo cueros, cabezas, de hasta tres guanacos que habían matado ese fin de semana; y más allá estaban las patitas pequeñitas, se ve que había matado hembras preñadas". En este sentido, nuestro entrevistado establece una diferencia entre el exencargado y sus compañeros de caza -estos últimos referidos como "gente de afuera" (i.e. no locales) por otros de nuestros informantes (N.Q., G.C.)- como cazadores "dañinos" 6 o "sin consciencia" y los "cazadores cazadores" (énfasis de P.Q.). Esta última expresión es utilizada para denominar a pobladores locales, hábiles en el arte de la caza, que la practican como una estrategia para complementar su alimentación y el ingreso familiar, además de comprender cuestiones culturales y tradicionales propias del lugar (ver Tamburini 2016; Manzano-García 2019). En contraste, N.Q. sugiere que F.P. probablemente "hacía plata", es decir, que habría lucrado ilegalmente liberando el campo para la caza. De hecho, diversas personas sabían que F.P. tenía "un arreglo" con carniceros locales, a quienes les vendía tanto la carne de res como de otros animales cazados (guanaco inclusive) para la confección de embutidos. Cabe destacar que nuestra red de interlocutores no nos ha posibilitado entrevistar a esta persona.

Por otro lado, la cacería practicada por los "dañinos" y las características de la acumulación ósea estudiada nos llevan a reflexionar sobre cómo concebimos el análisis del fenómeno estudiado, generalmente en una cadena operativa en la que se cuentan la caza y un primer procesamiento, el transporte, el trozado final y el descarte en un lugar determinado. ¿Pero qué pasa cuando el fenómeno tiene su inicio y su fin en el acto de matar un animal? Una 
lógica contraria a la preconizada por los "cazadores cazadores", pero que parece más acorde al contexto de "la gran aceleración" y su desapego del mundo habitado, propio de una ontología naturalista ${ }^{7}$. Cabe destacar que, a principios del siglo pasado, Río y Achával (1905) ya alertaban sobre este fenómeno:

\begin{abstract}
Por lo común, los guanacos, muy ariscos "no se dejan acercar" y son fusilados desde distancias suficientemente largas para hacer la caza tan infructuosa como perjudicial, porque si bien los cazadores rara vez consiguen capturar algunas piezas, en cambio casi siempre resultan muchos guanacos heridos sin provecho para nadie (Río y Achával 1905:342).
\end{abstract}

En línea con lo argumentado, las personas con quienes hemos hablado mencionan la presencia de tropillas de 15 a 40 guanacos en los años ochenta y noventa (ver también Manzano-García et al. 2019), mientras que en la actualidad no hemos observado tropillas de más de 10 individuos. Según I.G., un poblador de 92 años que trabajó en el obraje como hachero, solían salir "70 caballos persiguiendo tropas de 20 guanacos", una práctica muy parecida a la relatada por Río y Achával (1905:342): “diez, quince ó veinte cazadores provistos de armas de precisión salen á perseguirlos". Todo esto nos indica que la caza desarraigada ya se encontraba afianzada (o afianzándose) más de cien años atrás, fenómeno que asociamos a un largo proceso histórico cuyas raíces pueden rastrearse a la llegada de los europeos a la región en el siglo $\mathrm{XVI}^{8}$.

\section{La cacería en el campo}

Partiendo de ese corpus de información, los relatos de nuestros interlocutores y la evidencia material en el paisaje, hemos podido reconstruir el "itinerario" seguido por las personas involucradas en las actividades cinegéticas que formaron el Cementerio Ferrarini (Figura 2). Este consiste en un recorrido de ca. $25 \mathrm{~km}$ a lo largo del camino que bordea el perímetro del campo, comúnmente realizado en un vehículo desde donde se habrían efectuado los disparos "(...) con calibre grueso, más o menos a 150 m” (P.Q.) (Figura 3D) y a donde se habrían cargado los animales cazados. El procesamiento se habría realizado en el puesto, donde aún pueden observarse las huellas dejadas en el quebracho (Aspidosperma quebracho-blanco)
(Figura 3A y B), allí donde se colgaba a los animales para "cuerearlos" y "carnearlos" con cuchillos o con la ayuda de una sierra (Figura 3C). Como último eslabón del recorrido, las osamentas y despojos restantes habrían sido descartados unos $2 \mathrm{~km}$ al este del puesto, en el Cementerio Ferrarini, para evitar los hedores de la descomposición.

\section{Esqueletos de guanaco: zooarqueología del pasado reciente}

\section{Cuantificación y estado de conservación}

En cuanto a la acumulación de esqueletos de guanaco hallada en el Cementerio Ferrarini, su cuantificación dio por resultado un total de 377 especímenes (NISP) y un número mínimo de 363 elementos (MNE), debido al bajo grado de fragmentación de la muestra. Como hemos mencionado anteriormente, Costa y Barri (2018:Tabla S1) realizaron un análisis de la meteorización de parte del conjunto ( 20 falanges proximales, cinco mandíbulas y 19 cráneos), y propusieron una exposición no mayor a cuatro años ${ }^{9}$. No obstante, dado que en conjunto J.Z. y F.P. habrían trabajado en el campo entre mediados de la década de 1990 hasta 2013, es factible que parte de los restos recuperados en el sitio hayan permanecido expuestos por más tiempo que el planteado por los autores en aquella primera aproximación. Tampoco podemos descartar la posibilidad de que algunos restos no se hayan preservado o que fueran descartados en otros puntos del campo. De hecho, B.Z. nos ha mencionado la existencia de otra localidad de descarte, a la que no pudimos acceder ya que fue destruida en obras posteriores. Por su parte, L.G., quien comenzó a trabajar en el campo durante 2013, relata: “¡Había osamentas! Yo me metía por el medio del monte, había osamentas, guanacos muertos por todos lados. (...) Pero te aseguro que yo te llevo a la parte esa y ni existen los huesos ya".

Aquellos primeros resultados tafonómicos -correspondientes a menos de un 15\% del NISP de la colección trabajada- fueron complementados aquí, pero, en esta ocasión, unificando lo relevado sobre la base de los estadios propuestos por Behrensmeyer (1978). En la Figura 4 se pueden observar los distintos estadios de meteorización por elemento. En general, el estadio 0 prima en los elementos más compactos y pequeños, mientras que el estadio 1 se ve más representado en los elementos que componen la columna vertebral. Los huesos largos apendiculares presentan en mayor proporción el estadio 2 , evidenciado en un astillamiento 


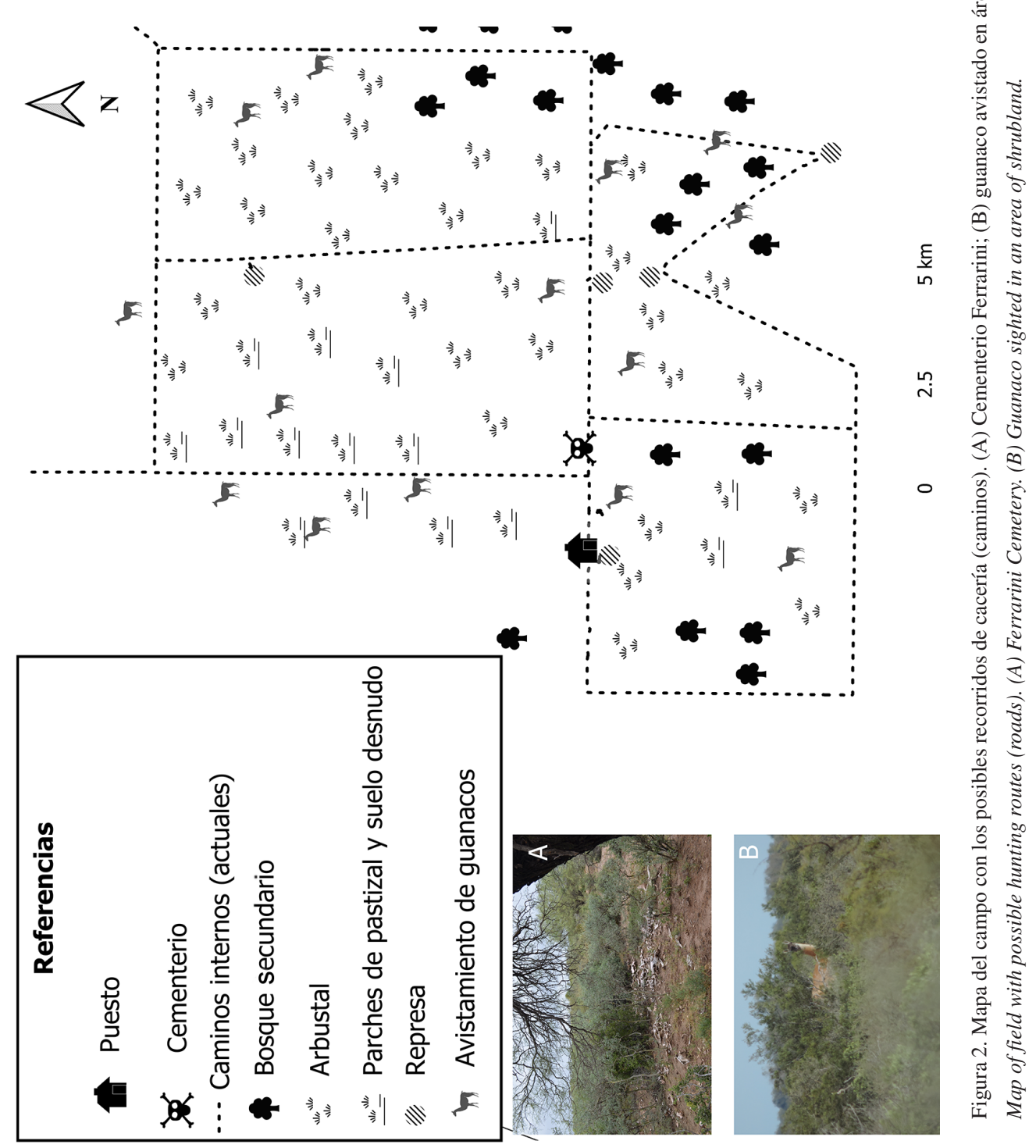




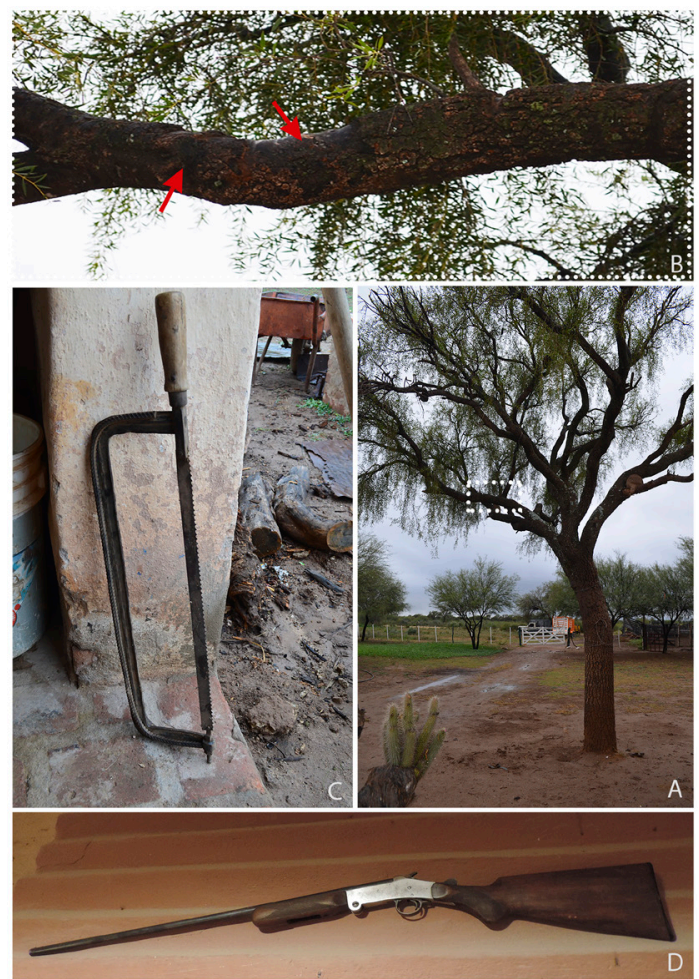

Figura 3. (A) El quebracho (Aspidosperma quebracho-blanco) donde se colgaban los animales para ser carneados; (B) detalle de la rama con marcas de desgaste en la corteza; (C) Sierra de mano utilizada en el procesamiento de los animales; (D) escopeta calibre 14 utilizada para cazar.

(A) The quebracho tree (Aspidosperma quebracho-blanco) where animals were hung for processing. (B) Detail of the branch with wear marks on the bark. (C) Handsaw used in animal processing. (D) 14-gauge shotgun used for hunting. más pronunciado y presencia de splitting; este estadio también se presenta en alrededor de un $40 \%$ de los cráneos. El estadio 3, por su parte, se encuentra representado en mucha menor medida, particularmente en cráneos, mandíbulas y vértebras cervicales. Pocos especímenes presentaron meteorización en estadio 4 , y estos corresponden en su mayoría al esqueleto axial, a excepción de una baja proporción de fémures y metatarsos. En general, consideramos que el perfil de meteorización obtenido responde, por un lado, a periodos de exposición diferenciales pero, por el otro, podría estar condicionado por algunas particularidades del ambiente local como la dinámica erosiva (pluvial y eólica) y la acción de la vegetación como mitigante de la meteorización (Borrero 2007; Cruz 2014), así como por las diferentes tasas de meteorización por elemento (Borrero 2007; Massigoge et al. 2014).

En el sitio aquí estudiado, el cálculo del número mínimo de individuos (MNI) -basado en los cráneosnos permitió estimar la presencia de al menos 23 guanacos descartados. Un número relativamente bajo si consideramos que los propietarios del campo asumieron a finales de la década de 1990 y habrían incentivado, más que la cacería, el exterminio de la competencia del ganado vacuno. En lo que a la construcción del perfil etario y sexual de la colección respecta, el gráfico resultante (Figura 5) apunta a una estrategia generalista de cacería, confirmando lo expuesto con anterioridad. El perfil presenta proporciones similares de ambos sexos: seis machos y siete hembras adultas (entre tres y ocho años).

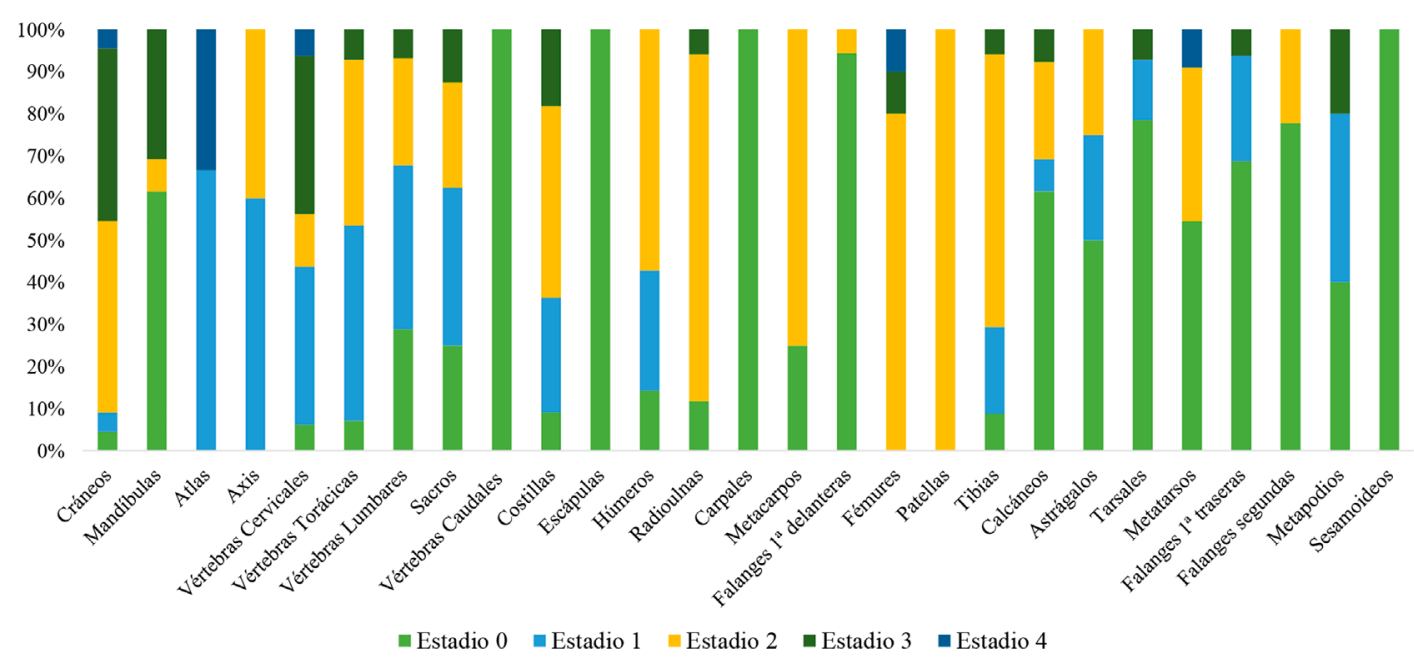

Figura 4. Estadios de meteorización de la colección según la propuesta de Behrensmeyer (1978).

Weathering stages of the collection according to Behrensmeyer's proposal (1978). 
5

4

3

2

1

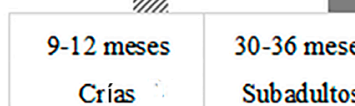

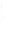

1

Hembras

a Indeterminados

Figura 5. Perfil etario y sexual de los cráneos recuperados en el sitio cementerio. El individuo cría (diferenciado con líneas oblicuas) corresponde a la osamenta hallada por fuera del Cementerio Ferrarini, denominado como F1.

Age and sexual profile of the skulls recovered at the cemetery site. The subadult individual (differentiated using oblique lines) corresponds to the bones found outside the Ferrarini Cemetery, called F1.

Además, fueron identificados siete individuos de sexo indeterminado: cinco subadultos, dos adultos y una cría. Esta última corresponde al individuo F1, recuperado por fuera del Cementerio Ferrarini y que fue encontrado por nuestros interlocutores agonizando en un alambrado y, en consecuencia, sacrificado.

Tras lo expuesto, nos es posible afirmar que los resultados sobre la composición etaria-sexual de la colección se condicen con algunos relatos sobre ciertas prácticas de cacería "sin consciencia" o "dañinas", como menciona G.C. Además, nuestros colaboradores señalan que tanto F.P. como J.C. salían con dos o más personas movilizados en vehículo, desde donde se disparaba a los animales sin muchos reparos en términos de la elección de la presa, "por deporte, por diversión, por depredar, porque no tienen consciencia de lo que es el guanaco", en palabras de uno de nuestros interlocutores (P.Q.).

En la Figura 6 ilustramos, por un lado, la frecuencia estandarizada de unidades anatómicas mínimas (MAU\%) de la muestra y, por el otro, un mapa de calor donde se pueden observar las concentraciones de huellas de procesamiento y que, a la vez, da cuenta de la distribución diferencial de las mismas en las distintas secciones de cada elemento. Esa distribución fue interpretada en conjunto con los datos cuantitativos presentados en las Tablas 1, 2 y 3. Es importante destacar que la correlación entre el MAU\% del conjunto de adultos $(76,39 \%$ de la muestra) y los valores de densidad mineral ósea (sensu Stahl 1999) indican una asociación débil entre ambas variables y estadísticamente no significativa $\left(r_{\mathrm{s}}=0,03 p=0,72\right)$. Considerando las discusiones vigentes en torno a la variabilidad intrataxonómica de la densidad mineral ósea (ver Gutiérrez et al. 2010; Izeta 2005), el resultado de esta correlación no es tomado como definitivo sino como un primer acercamiento a este proceso tafonómico que debe ser interpretado críticamente a la luz de otras variables tafonómicas (Gutiérrez et al. 2010).

\section{Elementos óseos y sus usos locales}

Para empezar, el hecho de que los cráneos sean el elemento mejor representado (Figura 6A) no es un dato menor. Es recurrente escuchar que "el cráneo no se come" (L.G., N.Q.) porque tiene poca carne, a diferencia del de otras especies como el jabalí. En este sentido, sería esperable encontrar marcas de corte en el área occipital, atlas o axis, que denotaran la desarticulación de esta porción anatómica para su posterior descarte (Nilssen 2000). Sin embargo, en nuestro caso ubicamos huellas de este tipo en tan solo un cráneo, en el área occipital del mismo (Tabla 1 y Figura 6B). Además, los cráneos recuperados no presentan modificaciones causadas por carnívoros, sugiriendo que estos tampoco los consumen (Tabla 1), en consonancia con lo observado por Behrensmeyer y Dechant Boaz (1980:85) en sus estudios tafonómicos naturalistas. 

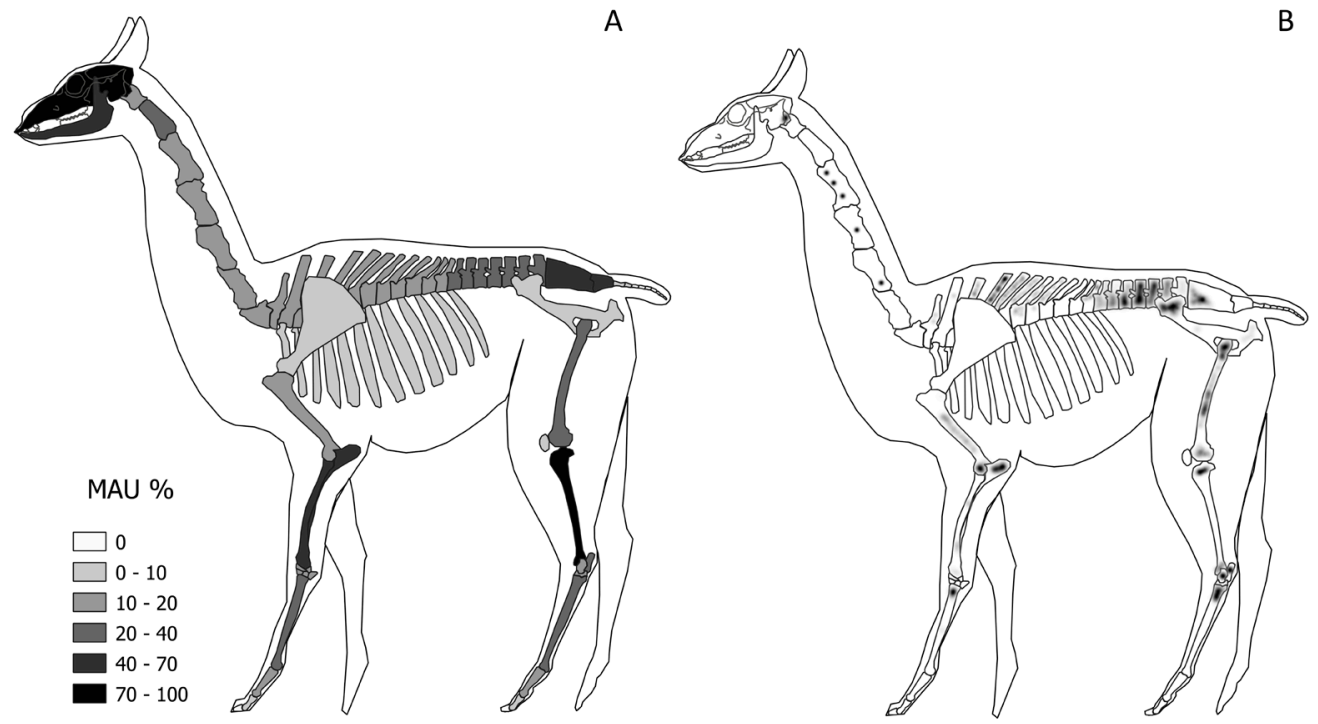

Figura 6. Esquema de guanacos representando: (A) unidades anatómica mínimas porcentuales (MAU\%); (B) mapa de calor evidenciando las áreas con mayores concentraciones de huellas de procesamiento antrópico.

Guanaco scheme representing: (A) Percentage of minimum number of anatomical units (MAU\%, left); (B) Heat map showing the areas with high concentrations of anthropic processing tracks.

Las vértebras cervicales - "el cogote", en términos locales- se presentan en baja frecuencia (NISP=24, incluyendo atlas y axis). Un hecho llamativo, posiblemente asociado a la acción de carroñeros ${ }^{10}$, ya que el cuero del cogote es apreciado como materia prima para realizar lazos, látigos (P.Q. y L.G.), el trenzado de las boleadoras (R.M. y J.R.) y cabrestos (D.R.). En efecto, según otro de nuestros entrevistados (I.G.), el cuero del cuello del guanaco es sumamente resistente, por lo que es utilizado para fabricar "trenzas de trece" y bozales (Manzano-García et al. 2019:37). Por otra parte, la cantidad de marcas registradas en las cervicales recuperadas en el sitio es muy baja (Tabla 1), y es interesante destacar que si bien tres de ellas podrían estar relacionadas a marcas de "cuereo", las otras dos consisten en aserrados que posiblemente respondan al descarte de la cabeza del animal y podrían explicar la baja frecuencia de marcas en los cráneos.

En las vértebras torácicas, en cambio, la presencia de marcas es mayor ( $\mathrm{N}=59$ en 28 elementos, Tabla 1 ). De acuerdo a lo planteado por Nilssen (2000:79), sería esperable encontrar mayor cantidad de marcas en las apófisis transversas de estos elementos, sin embargo, el 90\% de las marcas que hemos relevado se encuentra concentrado en las apófisis espinosas. En nuestro caso, las marcas responderían a la extracción de la porción de carne conocida como "lomo", es decir, que estarían respondiendo a la misma intención registrada en las vértebras lumbares (ver más adelante). Además, Nilssen (2000:80) señala que este tipo de fileteo produce una baja frecuencia de marcas, ya que el carnicero se limita a cortar tejidos conectivos y no entra en contacto directo con el hueso.

En cuanto a las vértebras lumbares, la concentración de marcas es alta ( $\mathrm{N}=368$ en 61 elementos, Tabla 1$)$, lo cual cobra sentido si se considera la gran cantidad de carne presente en el lomo de estos animales, evidenciada también en el MGUI $(44,9)$ propuesto por Borrero (1990b) para esta porción anatómica. Esta cantidad de marcas, en tanto, parece remitir a un mayor esfuerzo por extraer la carne adherida a la porción ventral de los cuerpos vertebrales, en las apófisis transversas, donde se encuentra concentrada la mayor cantidad de marcas (Figura 6B).

Diversas preparaciones pueden realizarse con carne de guanaco según nuestros entrevistados. Las "milanesas" son comúnmente mencionadas en el área, generalmente realizadas con "la pata" del animal ${ }^{11}$. Sin detallar qué fracciones utilizaría para cada preparación, N.Q. afirma que la carne del guanaco es buena "para guiso o hacer una milanesa". A su vez, L.G. también menciona la segunda opción y ambos concuerdan en que no es carne buena para el asado, "es como 
Tabla 1. Número de especímenes identificados (NISP) para cada elemento, NISP con marcas antrópicas, porcentaje de especímenes con marcas antrópicas, cantidad $(\mathrm{N})$ de marcas relevadas y porcentaje de especímenes con marcas de carnívoros. Number of specimens identified (NISP) per element, NISP with anthropic marks, percentage of specimens with anthropic marks, number $(N)$ of marks recorded per element, and percentage of specimens showing carnivore marks.

\begin{tabular}{|c|c|c|c|c|c|}
\hline Elemento & NISP & $\begin{array}{l}\text { NISP con marcas } \\
\text { antrópicas }\end{array}$ & $\begin{array}{l}\% \text { con marcas } \\
\text { antrópicas }\end{array}$ & $\begin{array}{l}\mathrm{N} \text { de marcas } \\
\text { antrópicas }\end{array}$ & $\begin{array}{l}\text { \% con marcas de } \\
\text { carnívoros }\end{array}$ \\
\hline Cráneos & 23 & 1 & 4,35 & 2 & 0,00 \\
\hline Mandíbulas & 14 & 0 & 0,00 & 0 & 7,14 \\
\hline Hioideos & 2 & 0 & 0,00 & 0 & 0,00 \\
\hline Atlas & 3 & 0 & 0,00 & 0 & 33,33 \\
\hline Axis & 5 & 0 & 0,00 & 0 & 40,00 \\
\hline Vértebras cervicales & 16 & 3 & 18,75 & 5 & 37,50 \\
\hline Vértebras torácicas & 28 & 13 & 46,43 & 59 & 21,43 \\
\hline Vértebras lumbares & 61 & 42 & 68,85 & 368 & 24,59 \\
\hline Sacros & 10 & 6 & 60,00 & 14 & 60,00 \\
\hline Vértebras caudales & 2 & 1 & 50,00 & 4 & 0,00 \\
\hline Costillas & 11 & 0 & 0,00 & 0 & 0,00 \\
\hline Escápulas & 1 & 0 & 0,00 & 0 & 0,00 \\
\hline Húmeros & 9 & 3 & 33,33 & 37 & 44,44 \\
\hline Radioulnas & 19 & 5 & 26,32 & 18 & 47,37 \\
\hline Carpales & 14 & 0 & 0,00 & 0 & 0,00 \\
\hline Metacarpos & 12 & 3 & 25,00 & 7 & 0,00 \\
\hline Falanges $1^{\mathrm{a}}$ delanteras & 18 & 0 & 0,00 & 0 & 0,00 \\
\hline Innominados & 2 & 2 & 100,00 & 21 & 100,00 \\
\hline Fémures & 12 & 6 & 50,00 & 25 & 33,33 \\
\hline Patelas & 3 & 0 & 0,00 & 0 & 0,00 \\
\hline Tibias & 35 & 1 & 2,86 & 5 & 51,43 \\
\hline Calcáneos & 13 & 1 & 7,69 & 1 & 7,69 \\
\hline Astrágalos & 8 & 1 & 12,50 & 1 & 0,00 \\
\hline Tarsales & 14 & 0 & 0,00 & 0 & 0,00 \\
\hline Metatarsos & 11 & 2 & 18,18 & 10 & 0,00 \\
\hline Falanges $1^{\mathrm{a}}$ traseras & 16 & 0 & 0,00 & 0 & 0,00 \\
\hline Falanges segundas & 9 & 0 & 0,00 & 0 & 0,00 \\
\hline Metapodios & 5 & 0 & 0,00 & 0 & 20,00 \\
\hline Sesamoideos & 1 & 0 & 0,00 & 0 & 0,00 \\
\hline Total & 377 & 90 & 23,87 & 577 & 15,65 \\
\hline
\end{tabular}

Tabla 2. Marcas antrópicas relevadas en húmeros y fémures del individuo $\mathrm{F} 1$ y los elementos recuperados en el sitio cementerio. Entre paréntesis, el número de especímenes que conforma cada conjunto.

Anthropic marks identified on the humerus and femurs of individual F1 and the elements recovered at the cemetery site. In brackets, the number of specimens that make up each set.

\begin{tabular}{ccc}
\hline \multirow{2}{*}{ Elemento } & \multicolumn{2}{c}{ Colección } \\
\cline { 2 - 3 } & F1 & Cementerio Ferrarini \\
\hline Húmero & $26(2)$ & $11(7)$ \\
\hline Fémur & $17(2)$ & $8(10)$ \\
\hline
\end{tabular}

Tabla 3. Tipos de alteraciones antrópicas relevadas y frecuencia con relación a los especímenes.

Types of anthropic alterations recorded and frequency in relation to specimens.

\begin{tabular}{lcccc}
\hline $\begin{array}{c}\text { Tipo de } \\
\text { marcas de } \\
\text { procesamiento }\end{array}$ & $\begin{array}{c}\text { NISP } \\
\text { con } \\
\text { marcas }\end{array}$ & $\begin{array}{c}\text { Cantidad } \\
\text { de } \\
\text { marcas }\end{array}$ & $\begin{array}{c}\text { Frecuencia } \\
\text { respecto al } \\
\text { NISP total }\end{array}$ & Porcentaje \\
\hline Cortes & 77 & 545 & 1,47 & 98,02 \\
\hline Aserrados & 9 & 11 & 0,03 & 1,98
\end{tabular}


la cabra del monte, carne seca" (L.G.). No obstante, esta última valoración no es compartida por todos nuestros entrevistados, algunos de los cuales sí han mencionado que el ungulado puede ser consumido en el asado (D.R., R.F. y G.C.), mientras que otros remarcan que también es buena carne para hacer charqui (R.F. y G.C.).

En relación a las costillas, son varios los puntos a considerar. Teniendo en cuenta el MGUI de Borrero (1990b), esta porción anatómica presenta el valor máximo (100) dentro de la escala. En efecto, el MAU\% obtenido para estos elementos dentro del conjunto fue de 1,99. Esto podría deberse, por un lado, a que los costillares fueron llevados completos para su consumo en otro lugar, lo que explicaría su baja frecuencia en el sitio. Por otra parte, no podemos ignorar el hecho de que las costillas son elementos susceptibles a procesos tafonómicos como la meteorización, pisoteo y acción de carnívoros, situaciones que influyen en la recuperación de estos elementos (Borrero 1990a; Massigoge et al. 2014). Con respecto a lo anterior, uno de nuestros interlocutores manifestó que se suelen tirar los costillares a los perros (N.Q.), hecho llamativo si pensamos en términos netamente "económicos"12 (algo que quizás no deberíamos hacer).

En lo que respecta a los elementos apendiculares, es notable que tanto para los apéndices anteriores como posteriores, los elementos con mayor proporción de huellas antrópicas también presentan las cantidades más altas de modificaciones por carnívoros, particularmente perros, lo que parece asociarse a una práctica cultural que implica recompensar al compañero de cacería (N.Q., L.G.) ${ }^{13}$. Asimismo, los cánidos suelen volver a los sitios de descarte en busca de huesos, alterando y desplazando estos elementos (véase Kent 1993). Volviendo a las modificaciones antrópicas, es notable que tanto el húmero (MGUI 23,8) como el fémur (MGUI 83,2) fueron los elementos con mayor cantidad de marcas, poniendo en evidencia una práctica de fileteo y aprovechamiento de carne (esto se evidencia principalmente en el individuo F1, como se tratará a continuación).

La presencia de diversas personas involucradas en el procesamiento, como mencionan algunos entrevistados en relación a las prácticas de F.P., podría evidenciarse en las distintas huellas relevadas en los restos óseos. Esta distinción solo pudo observarse de manera clara al comparar ciertos elementos del individuo $\mathrm{F} 1$, de procedencia y procesamiento conocidos, con los elementos recuperados en el Cementerio Ferrarini. El primero, como ya fue expuesto, fue procesado por dos lugareños, que afirman ser "unos inútiles" en este tipo de tareas. A los fines de contrastar las prácticas de procesamiento e inferir acerca del aprovechamiento de los animales, húmeros y fémures fueron los elementos seleccionados (Tabla 2); otros elementos no nos permitieron realizar esta comparación debido a la baja o nula frecuencia de marcas en una o ambas muestras.

Comenzando por los húmeros, $\mathrm{F} 1$ presentó un total de 26 huellas de corte (Tabla 2), 23 de las cuales se concentraron en las diáfisis de ambos elementos (derecho e izquierdo) y se encuentran asociadas al fileteo de esta porción anatómica -información que nos fue provista por nuestros entrevistados (P.Q. y L.G.)- y otras tres ubicadas en el extremo distal del húmero derecho. En contraposición, en el Cementerio Ferrarini se hallaron siete húmeros, seis de los cuales no presentaron marca alguna, y un único elemento (catalogado 295) con 10 marcas en el extremo distal y una marca en el extremo proximal (Tabla 2), posiblemente relacionadas a la desarticulación (Binford 1981), pero que también podrían haber surgido durante actividades de fileteo (Nilssen 2000).

Para el caso de los fémures, si bien presentan menor cantidad de huellas de procesamiento, F1 también concentra la mayor cantidad de modificaciones (Tabla 2), ocho de ellas localizadas en las diáfisis de ambos elementos (derecho e izquierdo) y las restantes nueve distribuidas en los extremos proximales y distales. En contraste, ocho huellas de procesamiento fueron relevadas en un total de 10 fémures pertenecientes al conjunto de Cementerio Ferrarini, de los cuales solo cuatro presentaron marcas efectivamente. La distribución de estas fue variando para cada elemento, pero en general se presentan de manera equitativa entre extremos proximales y distales y diáfisis. Siguiendo a Nilssen (2000), podríamos argumentar que las modificaciones por procesamiento identificadas en estos elementos no son concluyentes para interpretar la actividad, dado que podrían asociarse tanto a la desarticulación como al fileteo de esta porción anatómica o, por qué no, a ambas acciones.

A fines comparativos, en la Figura 7 se muestran las huellas de corte relevadas en húmeros y fémures izquierdos. En negro se encuentran representadas las huellas registradas en el guanaco F1, mientras que las marcas en color blanco refieren a dos fémures (catalogados como 216 y 294) y un húmero (295) provenientes del Cementerio Ferrarini. Retomando lo expuesto con anterioridad, la inexperticia alegada por nuestros interlocutores podría explicar la mayor 


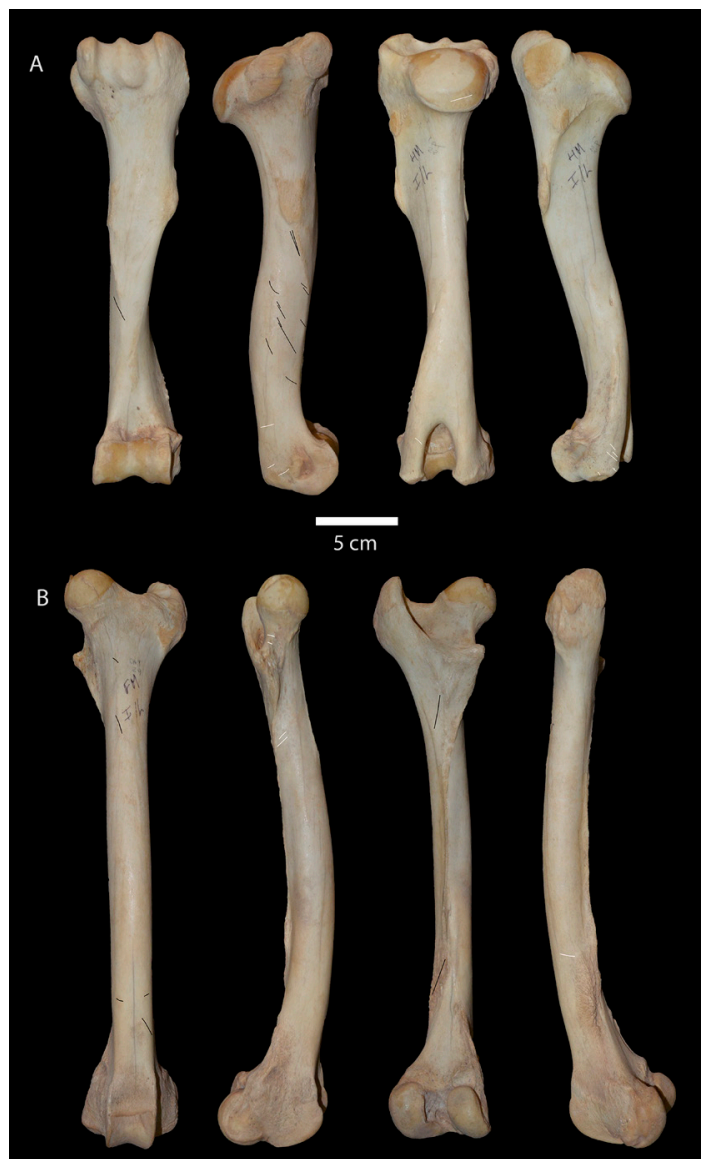

Figura 7. Modificaciones antrópicas (cortes) relevadas en los elementos húmero (A) y fémur (B) izquierdos. En color negro se representan las alteraciones encontradas en el individuo F1 (realizadas por dos entrevistados) y en color blanco en elementos del sitio cementerio (realizados en diversos momentos y probablemente por diferentes personas).

Anthropic modifications (cuts) identified on the left humerus (A) and femur (B) elements. Shown in black are the alterations found on the individual F1 (made by two interviewees) and, in white, those on elements from the cemetery site (made at different times and probably by different people).

cantidad de huellas de corte dejadas en ambos elementos en comparación con las halladas en el sitio, algo que ya ha sido discutido por otros autores (Barba y Domínguez-Rodrigo 2008; Lupo 2009). Si bien el húmero 295 no presenta grandes diferencias con el húmero de F1, entendemos que las prácticas que dieron origen al Cementerio Ferrarini variaron a lo largo del tiempo e involucraron a diversos actores con mayor o menor experticia. Además, el hecho de que solo uno de los 10 húmeros recolectados presente marcas de procesamiento podría responder a la acción de personas con más experiencia o bien a un escaso o nulo aprovechamiento de las carcasas allí descartadas, una práctica que fue recordada por algunos de nuestros entrevistados (L.G., B.Z.).

En línea con lo anterior, el uso de la sierra de mano (Figura 3C), evidenciado únicamente en nueve restos (Tabla 3), también podría relacionarse a la falta de destreza a la hora de desarticular una carcasa (P.Q.). Sin embargo, la utilización de esta herramienta también podría estar ligada a la necesidad de disminuir carcasas grandes, facilitando de esa manera su manejo durante otras actividades (Nilssen 2000:157). Es interesante resaltar que la cantidad de marcas de corte con cuchillo supera con creces a la de aserrados registrados, distribuidos en un número de especímenes mucho menor (Tabla 3), hecho esperable ya que el procesamiento con cuchillos puede involucrar tareas variopintas como el cuereo, el fileteo o la desarticulación, mientras que el uso de la sierra de mano estaría reservado únicamente para la separación de distintas porciones anatómicas sin la necesidad de lidiar con las articulaciones.

Como muestra la Figura 8, los especímenes aserrados corresponden a articulaciones del esqueleto apendicular-específicamente, parte de un corvejón con patología que pudo ser remontado en el laboratorio (8B)- y a distintos sectores de la columna vertebral (8A). Dentro de este pequeño conjunto de especímenes aserrados, destaca la presencia de tres sacros con evidencias de aserrados en el sector de las alas (8C) y en la porción distal del elemento, es decir, a la altura de la última vértebra sacral. Esto podría deberse a la desarticulación de este elemento, de la fracción posterior del animal, y al corte y posterior descarte del rabo, respectivamente. Por otra parte, a pesar de que platos hervidos, como "los guisos", han sido mencionados como preparaciones comunes con carne de guanaco, los aserrados relevados en el sitio parecen más relacionados con la disminución de las carcasas para facilitar su manipulación que con estos preparados, cuyas evidencias han sido observadas de manera más clara en contextos rurales norteamericanos (Tuma 2006). Además, según los relatos, el Cementerio Ferrarini habría sido un lugar de descarte de las carcasas luego de un procesamiento primario que habría tenido lugar en el puesto (aunque las prácticas pueden haber variado en los distintos eventos de caza).

\section{Otros usos: la medicina regional}

Continuando con los usos y valoraciones ligados al guanaco en la región, creemos interesante destacar el uso medicinal de la fibra y las patas de guanaco 


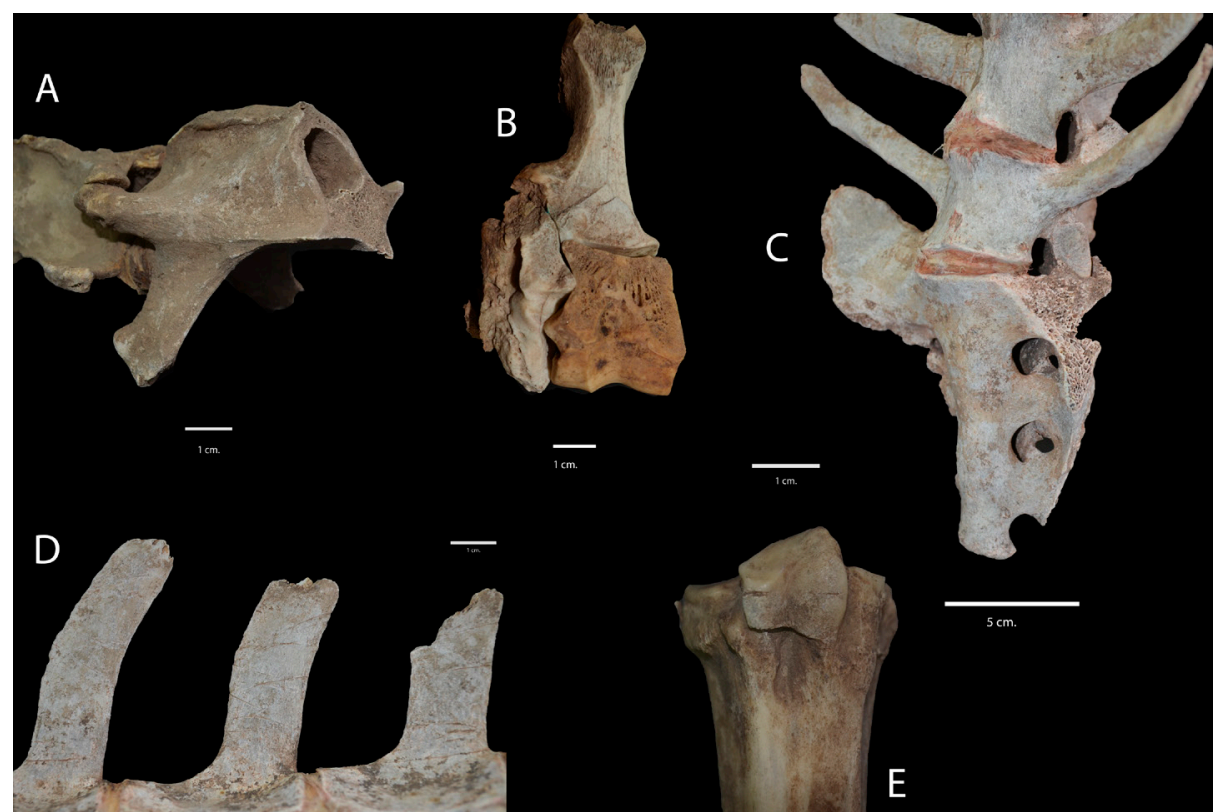

Figura 8. Huellas antrópicas relevadas: (A) Aserrado sobre vértebra cervical; (B) aserrado sobre calcáneo y tarsales; (C) aserrado sobre sacro; (D) cortes de instrumento metálico en vértebras lumbares; (E) cortes en epífisis proximal de metatarso.

Anthropic marks: (A) Saw marks on the cervical vertebra. (B) Saw marks on the calcaneus and tarsal. (C) Saw marks on the sacrum. (D) Metal instrument cuts on the lumbar vertebrae. (E) Cuts on the proximal metatarsal epiphysis.

(autopodios), práctica que ya ha sido discutida en trabajos previos (Manzano-García 2019; ManzanoGarcía et al. 2019). El pelaje suele ser utilizado para el dolor de oído, especialmente infantil (P.Q., G.V., S.D., J.Q.), y la forma de uso puede variar. En algunos casos mencionan la disposición de la fibra sin tratamiento previo y en otros, calentando una porción de la fibra en aceite y posteriormente introduciéndola en el oído afectado. Así lo narran G.V. y S.D.: "agarrás un poquito de lana la hacés un bollito, la calentás en aceite y luego se la ponés al niño en el oído".

Respecto al uso de la pata del animal, esta práctica consiste en la cura de la parálisis facial, conocida localmente como "el aire", "rama de oro" o "ACV" (siglas de accidente cerebrovascular), mediante rezos $\mathrm{y}$ friccionando las almohadillas de la pata en sentido contrario al de la parálisis (B.Z., G.C., G.V., V.S., N.G., M.S., J.Q.). En palabras de G.C., "la pata es buena para cuando se ladea la boca, se roza por la cara", haciendo referencia a esta afección (ManzanoGarcía et al. 2019:36).

En la Figura 9, presentamos un mapa que ilustra la circulación actual de patas de guanacos que fueron cazados en el área de estudio y que son prestadas entre vecinos, conocidos y no tan conocidos, viajando en ocasiones por varios años de casa en casa ${ }^{14} \mathrm{e}$ incluso por distintos poblados de la región. Esta circulación de patas de guanaco a través de contextos domésticos pone de manifiesto un entramado social que se extiende por al menos $2.000 \mathrm{~km}^{2}$, conectando las localidades de Villa de Soto, La Batea, Serrezuela, Piedrita Blanca y El Milagro (esta última en la Provincia de La Rioja). Además, estas prácticas ponen en evidencia un amplio conocimiento acerca de los beneficios terapéuticos de diferentes especies autóctonas, tanto animales como vegetales (Manzano-García 2019). Por esta razón, hemos planteado que las valoraciones y usos de los guanacos son amplios y multitemporales, manifestándose tanto en el registro arqueológico prehispánico como en el pasado contemporáneo de la región (Manzano-García et al. 2019).

En relación a lo expuesto, el hecho de rescatar esta práctica de raigambre local no significa en modo alguno que la consideremos explicativa del bajo MAU\% de los elementos que componen el autopodio (Figura 6A) registrado en el Cementerio Ferrarini, sino que nos permite reflexionar acerca de otros usos que exceden la alimentación. En esta línea, Yacobaccio y colaboradores (1998) han documentado 


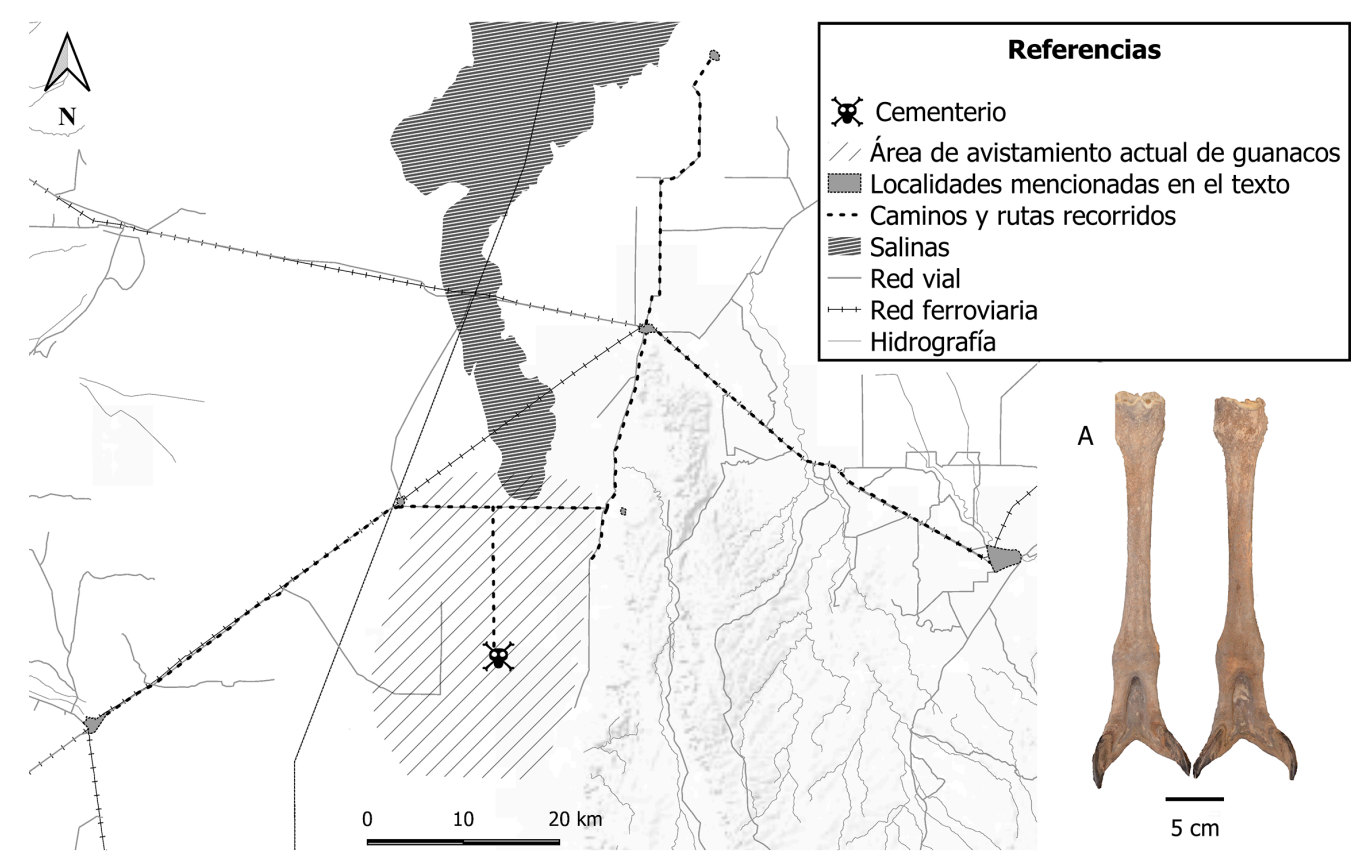

Figura 9. Localización del cementerio y área actual de distribución de los guanacos, en relación a las localidades en que se recopilaron relatos acerca de la utilización de autopodios en la medicina regional. (A) Representación de las unidades anatómicas como son utilizadas por las comunidades en la práctica medicinal.

Location of the cemetery and current area of distribution for guanacos in relation to the localities where stories about the use of autopodia in regional medicine were collected. (A) Representation of anatomical units as used by communities in medicinal practice.

que estos apéndices suelen ser guardados en los sitios estacionales de los pastores puneños, aparentemente para su consumo a posteriori. Estos autores señalan que los autopodios son comúnmente encontrados tanto en las bases residenciales como en los puestos estacionales de pastoreo, estos últimos habitados solo durante el verano (Yacobaccio et al. 1998). Prácticas actuales como estas nos llevan a pensar cómo dichas unidades anatómicas, tan recurrentes en el registro arqueológico, son utilizadas y conservadas en diferentes contextos y con diversas finalidades.

\section{Zooarqueología políticamente orientada}

A lo largo del trabajo, hemos intentado demostrar que los cambios predatorios que vimos aquí venían estableciéndose, al menos, desde fines del siglo XIX o principios del XX. A nuestro entender, estas alteraciones vienen ocurriendo desde el arribo de los primeros europeos con sus ideas civilizatorias ${ }^{15}$, que excluyeron la fauna autóctona sustituyéndola por la europea y transformándola en plaga a ser combatida. Los "patrones" foráneos incentivando la aniquilación de los guanacos en sus campos representan un buen ejemplo de esta visión acerca de la fauna autóctona.

Por otro lado, las prácticas cinegéticas que dieron lugar a la formación del Cementerio Ferrarini nos reafirman lo previamente planteado por Tamburini (2016) en su trabajo sobre las estrategias de reproducción social del campesinado en nuestra región de estudio. Esta autora argumenta que la relación humano-fauna se encuentra sujeta a fuertes transformaciones y contradicciones, como consecuencia de los cambios socioeconómicos y ecológicos que se han sucedido en los últimos años y continúan sucediéndose -de manera cada vez más acelerada- en la actualidad. A pesar de esas evidentes transformaciones, desde nuestra experiencia destacamos que las percepciones en torno a los animales del monte son, en general, positivas $^{16}$ (Manzano-García 2019). A este respecto, es importante que se comprenda el potencial de esta estrecha relación para el desarrollo de planes de conservación participativos, es decir, que incluyan a las comunidades y su conocimiento vivencial en estos esfuerzos (Álvarez y Heider 2019; ManzanoGarcía y Martínez 2017; Manzano-García et al. 2019). 
En relación a lo anterior, resulta interesante remitirnos a la ley de creación de la Reserva Arqueológica Provincial de Guasapampa (Ley N ${ }^{\circ} 10308$, B.O. 28.10.2015), la cual entiende como bien arqueológico "toda la información medioambiental relacionada con la actividad humana (...) susceptibles de ser investigados con la aplicación de las técnicas propias de la arqueología", incluyendo los "aspectos intangibles que hacen a formaciones humanas prehispánicas hasta épocas recientes". En tanto, reconociendo el carácter multitemporal de estas interacciones, consideramos que los guanacos de Córdoba deberían ser considerados patrimonio histórico, natural y cultural de la provincia, ya que se encuentran en peligro crítico de extinción a nivel regional y necesitan una legislación específica que vele por su conservación ${ }^{17}$.

Por otro lado, etimológicamente la palabra Chaco remite a un paisaje concebido como territorio de caza (Paz Esquerre 2016), denotando la cercana relación entre los grupos humanos que han habitado la región a lo largo del tiempo, con las prácticas cinegéticas. De hecho, como ya fue expuesto, la cacería practicada por la gente local supone un conocimiento profundo de las especies animales con las que se relacionan, y una preocupación por sus respectivos ciclos de vida y reproducción ${ }^{18}$. Es por ello que juzgamos pertinente y necesario que la caza de subsistencia practicada por los pobladores locales sea considerada parte del patrimonio inmaterial local ${ }^{19}$.

Aunque la legislación provincial vigente contempla la situación de personas que "se dediquen a actividades... de caza, pesca y/o recolección, que utilicen mano de obra individual y/ o familiar" (Ley $\mathrm{N}^{\circ} 9814$ Ordenamiento Territorial de Bosques Nativos de la Provincia de Córdoba $^{20}$ ), la ley que regula la cacería comercial y de control de plagas desconoce y prohíbe aspectos de la caza local como el uso de perros, palos y cuchillos. En paralelo, avala la caza con armas de fuego -que demanda mayores recursos económicos- de ciertas especies introducidas en distintos sectores de la provincia, exceptuando el área de estudio aquí en cuestión (véase Decreto de Ley 4046-C-58 ${ }^{21}$ ). De hecho, en lo que al guanaco respecta, ni siquiera reconoce su existencia, al prohibir "en toda época la caza y comercio de animales pelíferos silvestres y de sus pieles y despojos, como nutria, llama", o al menos ignora las diferencias con su contraparte doméstica, la llama, hecho que pone en riesgo la conservación de la especie.

Como suele suceder, las leyes muchas veces desconocen las realidades locales, las prácticas culturales o el impacto que generan en la vida de las personas que no habitan los grandes centros urbanos, desde donde son escritas. La cuestión es que, a pesar de la legislación, la caza en esta región del Chaco árido se mantiene aún como un aspecto importante en la vida de sus pobladores, e incluso en muchos casos asegura el abastecimiento de carne para familias enteras. Por estas razones, creemos esencial seguir profundizando en esta problemática, para proponer maneras en que estas actividades puedan mantenerse en equilibrio con la conservación de la fauna endémica. Una alternativa podría ser la caza de especies introducidas, como el jabalí (Sus scrofa), acompañando la medida con instancias de intercambio de saberes en escuelas y municipios que permitan a las personas involucrarse en estas decisiones.

Cabe aclarar que no sugerimos un "control de plagas" como condenan los proponentes de la conservación compasiva (Wallach et al. 2018; 2020) ${ }^{22}$, sino una alternativa posible tanto para la conservación de las especies nativas como de las prácticas regionales. La opción nos parece viable si consideramos el mantenimiento de un equilibrio socioambiental en la región ${ }^{23}$.

Por último, sugerimos que es importante pensar las diversas prácticas culturales aquí retratadas -sean estas de cacería, consumo o medicinales- como una vía para entender mejor el impacto que ha tenido la era antropocénica en las relaciones entre humanos y guanacos. En este sentido, consideramos que los cambios negativos, asociados a la cacería deportiva (J.C., F.P.), la captura y venta de crías (N.P., P.M.) y demás negociados con los distintos productos del guanaco como la carne o la piel (B.Z., F.P.), combinados con la creciente deforestación del Chaco, el avance de la frontera agropecuaria, entre otras transformaciones de gran escala, han tenido un efecto devastador sobre la población de guanacos aquí estudiada. No obstante, las entrevistas también nos permitieron entrever resistencias a esos cambios como, por ejemplo, en el uso medicinal mencionado o en experiencias sentipensantes que denotan empatía o cercanía con estos animales. Como expresa G.A., remitiéndose a la mirada que sus abuelos tenían de los guanacos, "eran como sagrados, no era para hacerles daño" (Manzano-García et al. 2019:35).

\section{Consideraciones Finales}

A lo largo de este trabajo presentamos una metodología que integró los relatos y percepciones acerca de los guanacos, con análisis de restos óseos producto de la caza, procesamiento y descarte de estos 
ungulados. Este acercamiento nos permitió profundizar conocimientos sobre prácticas culturales (venatorias y de consumo), aspectos económicos e ideacionales de los pobladores en el área de estudio.

Basándonos en los resultados obtenidos, planteamos que las prácticas "dañinas" de cacería vienen instalándose al menos desde fines del siglo XIX. Asimismo, en algunos casos estas conductas parecen obedecer a presiones socioeconómicas típicas de nuestra era (p.ej., un patrón que quiere aumentar su producción, un campesino que necesita subsistir vendiendo productos del monte). En definitiva, las presiones impuestas por las actividades cinegéticas, en conjunto con la fragmentación del paisaje (resultado de las actividades de obraje y de ganadería), han puesto a los guanacos de la región en peligro de extinción a nivel local.

Para afrontar esta problemática, es necesaria una comprensión de los procesos históricos de mediano y largo plazo, y la arqueología puede contribuir mucho en esto. Además, entendemos que, para lograr la conservación de los guanacos, será necesario un equilibrio socioambiental local, y esa no será una tarea sencilla. Por lo tanto, el trabajo conjunto (con miembros de la comunidad y gestores públicos) e interdisciplinar se establece como una prioridad.

Por último, en este trabajo buscamos poner en evidencia que una (zoo)arqueología del pasado contemporáneo puede ser útil para abordar problemas del Antropoceno. En este sentido, acordamos con Olivier (2019:30) cuando afirma que el lugar de la arqueología es el "aquí y ahora". Aunque tratemos sobre el pasado, lo hacemos en el presente y esto demanda posicionarse y comprometerse políticamente en contra de los efectos devastadores de la gran aceleración.

Agradecimientos: Nuestro mayor agradecimiento está dirigido a la gente de Serrezuela, El Chacho, Piedrita Blanca, La Batea y El Milagro, que nos brinda su tiempo, nos abre las puertas de sus casas $y$, mate mediante, nos comparte sus conocimientos y responde a nuestras inquietudes. También agradecemos a Cristian Kaufmann por facilitarnos bibliografía útil, a Agustín Manes por sus sugerencias sobre la legislación provincial y a Fernando Barri y Lucila Castro por conversaciones que enriquecieron este trabajo. A nuestro lugar de trabajo, el Instituto de Antropología de Córdoba, Museo de Antropología, Facultad de Filosofías y Humanidades, Universidad Nacional de Córdoba, Consejo Nacional de Investigaciones Científicas y Técnicas. Este trabajo fue financiado por un Proyecto Formar de la Secretaría de Ciencia y Técnica de la UNC. Finalmente, agradecemos los valiosos comentarios de cuatro revisores que indudablemente ayudaron a mejorar la primera versión de este trabajo. Las fallas persistentes son de nuestra responsabilidad.

\section{Referencias Citadas}

Abe, Y., C.W. Marean, P.J. Nilssen, Z. Assefa y E.C. Stone 2002. The analysis of cutmarks on archaeofauna: a review and critique of quantification procedures, and a new image-analysis GIS approach. American Antiquity 67 (4):643-663.

Adams, W.H. 1983. Ethnoarchaeology as a merging of historical archaeological and oral history. North American Archaeologist 4 (4):293-305.

Albarella, U. 2011. Ethnozooarchaeology and the power of analogy. En Ethnozooarchaeology. The Present and Past of Human-Animal Relationships, editado por U. Albarella y A. Trentacoste, pp. 1-3. Oxbow Books, Oxford.

Albarella, U. y A. Trentacoste (eds.) 2011. Ethnozooarchaeology. The Present and Past of Human-Animal Relationships. Oxbow Books, Oxford.

Álvarez, M.C. y G. Heider 2019. Conocimiento tradicional y sus implicancias para la caza de jabalí y ñandú en comunidades campesinas del sur de la provincia de San Luis, Argentina. Etnobiología 17 (1):5-17.

Arenas, P. 2003. Etnografía y Alimentación entre los Toba Nachilamoleek y Wichí - Lhuku'tas del Chaco Central: Argentina. Edición del autor, Buenos Aires.

Barba, R. y M. Domínguez-Rodrigo. 2008. Nueva aproximación al estudio de las marcas de corte: definición de "zonas calientes"

como indicador de un consumo inicial de las carcasas por parte de los homínidos. Aplicación al conjunto de FLK Zinj (Olduvai). Complutum 19:9-24.

Behrensmeyer, A.K. 1978. Taphonomic and ecologic information from bone weathering. Paleobiology 4 (2):150-162.

Behrensmeyer, A.K. y D.E. Dechant Boaz 1980. The recent bones of Amboseli Park, Kenya, in relation to East African paleoecology. En Fossils in the Making: Vertebrate Taphonomy and Paleoecology, editado por A.K. Behrensmeyer y A.P. Hill, pp. 72-92. The University of Chicago Press, Chicago.

Bilbao, S.A. 1964-65. Poblamiento y actividad humana en el extremo norte del Chaco Santiagueño. Cuadernos del Instituto Nacional de Antropología 5:143-192.

Binford, L.R. 1978. Nunamiut: Ethnoarchaeology. Academic Press, New York.

Binford, L.R. 1981. Bones: Ancient Men and Modern Myths. Academic Press, Nueva York.

Borrero, L.A. 1990a. Taphonomy of guanaco bones in Tierra del Fuego. Quaternary Research 34 (3):361-371.

Borrero, L.A. 1990b. Fuego-Patagonia bone assemblages and the problem of comunal guanaco hunting. En Hunters of the Recent Past, editado por L.B. Davis y B.O.K. Reeves, pp. 373 406. Unwin Hyman, Londres. 
Borrero, L.A. 2007. Longitudinal taphonomic studies in Tierra del Fuego, Argentina. En Taphonomy and Archaeozoology in Argentina, editado por M.A. Gutiérrez, L. Miotti, G. Barrientos, G. Mengoni Goñalons y M. Salemme, pp. 219-233. BAR S1601. Archaeopress, Oxford.

Broderick, L. (ed.) 2016. People with Animals: Perspectives and Studies in Ethnozooarchaeology. Oxbow Books, Oxford.

Buchli, V. y G. Lucas. 2001. Archaeologies of the Contemporary Past. Routledge, Londres.

Cabido, M., S.R. Zeballos, M. Zak, M.L. Carranza, M.A. Giorgis, J.J. Cantero, A.T.R. Acosta 2018. Native woody vegetation in central Argentina: Classification of Chaco and Espinal forests. Applied Vegetation Science 21:298-311.

Carignano, C., D. Kröhling, S. Degiovanni y M.A. Cioccale 2014. Geomorfología. Relatorio del XIX Congreso Geológico Argentino, pp. 747-821. Asociación Geológica Argentina, Córdoba.

Costa, T. y F.R. Barri 2018. Lama guanicoe remains from the Chaco ecoregion (Córdoba, Argentina): An osteological approach to the characterization of a relict wild population. PloS One 13 (4):e0194727. https://doi.org/10.1371/journal.pone.0194727

Cruz, I. 2014. Estudios sobre meteorización de huesos en Patagonia. Revista Chilena de Antropología 29 (1):89-94.

Dargoltz, R.E. 2018 [1991]. Hacha y Quebracho. Historia Ecológica Social de Santiago del Estero. Marcos Vizoso, Santiago del Estero.

David, N. y C. Kramer 2001. Ethnoarchaeology in Action. Cambridge University Press, Cambridge.

Descola, P. 2001 [1996]. Construyendo naturalezas. Ecología simbólica y práctica social. En Naturaleza y Sociedad. Perspectivas Antropológicas, editado por P. Descola y G. Pálsson, pp. 101123. Siglo Veintiuno Editores, México D.F.

Dirección General de Estadística y Censos de la Provincia de Córdoba 2017. Síntesis CN2010 Departamento Minas. Gobierno de la Provincia de Córdoba, Córdoba.

Dirzo, R., H.S. Young, M. Galetti, G. Ceballos, N.J. Isaac y B. Collen 2014. Defaunation in the Anthropocene. Science 345 (6195):401-406.

Dos Santos Rodríguez, A. 2009. Metodología de la investigación etnozoológica. En Manual de Etnozoología. Una Guía Teórico Práctica para Investigar la Interconexión del ser Humano con los Animales, coordinado por E.M. Costa Neto, M. Vargas Clavijo, y D. Santos Fita. Tundra Ediciones, Valencia.

Driscoll, D.A. y M.J. Watson 2019. Science denialism and compassionate conservation: Response to Wallach et al. 2018. Conservation Biology 33 (4):777-780.

Escosteguy, P.D. 2011. Etnoarqueología de Nutrieros. Una Propuesta Metodológica Aplicada al Registro Arqueológico de la Depresión del Salado y del Noreste de la Provincia de Buenos Aires. Tesis doctoral, Facultad de Filosofía y Letras, Universidad de Buenos Aires.

Escosteguy, P.D. 2014. Estudios etnoarqueológicos con cazadores de coipo de Argentina. Antípoda. Revista de Antropología y Arqueología 20:145-165.
Fernández-Jalvo, Y. y P. Andrews 2016. Atlas of Taphonomic Identifications. 1001+ Images of Fossil and Recent Mammal Bone Modification. Springer, Dordrecht.

Gardenal Crivisqui, G. 2018. El Árbol y el Pescao. Personas, Animales y Plantas en el Monte Santiagueño. EDUNSE, Santiago del Estero.

Gasco, A.V., V. Durán, L. Piazze, M. Giardina y G. Campos 2015. Veranadas sin frontera. Etnografía de pastores en el Centro-Oeste argentino. Revista del Museo de Antropología 8 (2):133-146.

Giardina, M. 2010. El Aprovechamiento de la Avifauna entre las Sociedades Cazadoras-Recolectoras del sur de Mendoza: un Enfoque Arqueozoológico. Tesis doctoral, Facultad de Ciencias Naturales y Museo, Universidad Nacional de La Plata, La Plata.

González-Ruibal, A. 2017. Etnoarqueología, arqueología etnográfica y cultura material. Complutum 28 (2):267-283.

González-Ruibal, A. 2019. An Archaeology of the Contemporary Era. Routledge, Londres.

Gould, R. (ed.) 1978. Explorations in Ethnoarchaeology. University of New Mexico Press, Santa Fe, Nuevo México.

Gould, R. y M. Schiffer 1981. Modern Material Culture: The Archaeology of US. Academic Press, Nueva York.

Guber, R. 2001. La Etnografía Método, Campo y Reflexividad. Grupo Editorial Norma, Bogotá.

Guber, R. 2005. El Salvaje Metropolitano, Reconstrucción del Conocimiento Social en el Trabajo de Campo. Paidos, Buenos Aires.

Gutiérrez, M.A., C. Kaufmann, M. González, A. Massigoge y M.C. Álvarez 2010. Intrataxonomic variability in metapodial and femur bone density related to age in guanaco (Lama guanicoe). Zooarchaeological and taphonomical implications. Journal of Archaeological Science 37 (12):3226-3238.

Grayson, D.K. 1984. Quantitative Zooarchaeology: Topics in the Analysis of Archaeological Faunas. Academic Press, Nueva York.

Harrison, R. y E. Breithoff 2017. Archaeologies of the contemporary world. Annual Review of Anthropology 46:203-221.

Hodder, I. 1982. Symbols in Action: Ethnoarchaeological Studies of Material Culture. Cambridge University Press, Cambridge.

INDEC 2010. Censo Nacional de Población, Hogares y Viviendas. Instituto Nacional de Estadística y Censos de la República Argentina (INDEC), Buenos Aires.

Izeta, A.D. 2004. Zooarqueología del sur de los Valles Calchaquíes. Estudio de Conjuntos Faunísticos del Periodo Formativo. Tesis doctoral, Facultad de Ciencias Naturales y Museo, Universidad Nacional de La Plata, La Plata.

Izeta, A.D. 2005. South American camelid bone structural density: what are we measuring? Comments on data sets, values, their interpretation and application. Journal of Archaeological Science 32 (8):1159-1168. 
Kaufmann, C.A. 2009. Estructura de edad y sexo en Guanaco: Estudios Actualísticos y Arqueológicos en Pampa y Patagonia. Sociedad Argentina de Antropología, Buenos Aires.

Kent, S. 1993. Variability in faunal assemblages: The influence of hunting skill, sharing, dogs, and mode of cooking on faunal remains at a sedentary Kalahari community. Journal of Anthropological Archaeology 12:323-385.

Lefèvre, C., S. Lepetz y D. Legoupil 2003. ¿Cazadores terrestres, cazadores marítimos? Explotación de los recursos animales en el Locus 1. Cazadores-recolectores de Ponsonby (Patagonia austral) y su paleoambiente desde VI al III milenio A. C. Magallania 31:63-116.

Longacre, W.A. 1978. Ethnoarchaeology. Reviews in Anthropology $5: 357-363$

Lupo, K.D. 2009. Variability in cut mark attributes in ethnoarchaeological assemblages. En Zooarqueología y Tafonomía en el Confín del Mundo, editado por P. López Mendoza, I. Cartajena Fasting, C. García Pérez y F. Mena Larraín, pp. 27-44. Universidad Internacional Sek-Chile, Santiago.

Lyman, R.L. 1994. Quantitative units and terminology in zooarchaeology. American Antiquity 59:36-71.

Majewski, T. y M.B. Schiffer 2001. Beyond consumption: toward an archaeology of consumerism. En Archaeologies of the Contemporary Past, editado por V. Buchli y G. Lucas, pp. 26-50. Routledge, Londres.

Manzano-García, J. 2019. Etnoecología en Áreas Protegidas de la Ecorregión del Chaco Seco de Córdoba: Conocimiento, Uso y Conservación de la Biodiversidad Vinculada a la Subsistencia de sus Pobladores. Tesis doctoral, Facultad de Ciencias Exactas, Físicas y Naturales, Universidad Nacional de Córdoba, Córdoba.

Manzano-García, J. y G.J. Martínez. 2017. Percepción de la fauna silvestre en áreas protegidas de la provincia de Córdoba, Argentina: un enfoque etnozoológico. Etnobiología 15 (1):32-48.

Manzano-García, J., T. Costa, F.R. Barri y M.P. Weihmüller 2019. Interacciones entre el guanaco (Lama guanicoe) y el ser humano en el Gran Chaco: datos etnozoológicos pasados y actuales del noroeste de la provincia de Córdoba, Argentina. Etnobiología 17 (2):25-40.

Martín-Crespo, M.C. y A.B. Salamanca-Castro 2007. El muestreo en la investigación cualitativa. Nure investigación 27:1-4.

Massigoge, A., M.A. Gutiérrez, M.C. Álvarez, C.A. Kaufmann, D.J. Rafuse y M.E. González 2014. Estudio comparativo de las marcas de dientes producidas por dos pequeños carnívoros sudamericanos. Revista Chilena de Antropología 30:42-49.

Montes, A. 2008. Indígenas y Conquistadores de Córdoba. Compilado por C.J. Freytag. Ediciones Isquitipe, Buenos Aires.

Morello, J., W. Pengue y A. Rodríguez 2005. Etapas de usos de los recursos y desmantelamiento de la biota de chaco. En La Situación Ambiental Argentina, editado por A. Brown, U. Martínez-Ortiz, M. Acerbi y J. Corcuera. Fundación Vida Silvestre, Buenos Aires.

Natenzon C.E. y G. Olivera 1994. La tala del bosque en los llanos de La Rioja (1900-1960). Desarrollo Económico 34 (134):263-284.
Nilssen, P.J. 2000. An Actualistic Butchery Study in South Africa and its Implications for Reconstructing Hominid Strategies of Carcass Acquisition and Butchery in the Upper Pleistocene and Plio-Pleistocene. Tesis doctoral. Department of Archaeology, University of Cape Town, Ciudad del Cabo.

Olivier, L. 2019. The future of archaeology in the age of presentism. Journal of Contemporary Archaeology 6 (1):16-31.

Overton, N.J. y Y. Hamilakis 2013. A manifesto for a social zooarchaeology. Swans and other beings in the Mesolithic. Archaeological Dialogues 20 (2):111.

Otaola, C., M.A. Giardina, M. Fry, G.A. Neme y S. Wolverton 2016. Zooarqueologia y tafonomía en pastores actuales del sur de Mendoza. Intersecciones en Antropología 17:121-127.

Paz Esquerre, E. 2016. Huanchaco, identidad y tradición. Quingam 2:215-220.

Politis, G. y G. Martínez 1996. La cacería, el procesamiento de las presas y los tabúes alimenticios. En Nukak, editado por G. Politis, pp. 231-280. Instituto SINCHI, Santafé de Bogotá.

Politis, G. y N. Saunders 2002. Archaeological correlates of ideological activity: food taboos and spirit-animals in an Amazonian hunter-gatherer society. En Consuming Passions: Archaeological Studies of Material Culture, editado por P. Miracle y N. Milner, pp. 113-130. Mc Donald Institute or Archaeological Research, Cambridge.

Raedeke K.J. 1979. Population Dynamics and Socioecology of the Guanaco (Lama guanicoe) of Magallanes. Tesis doctoral, College of Forest Resources, University of Washington, Seattle.

Rathje, W.L. 1979. Modern material culture studies. Advances in Archaeological Method and Theory 2:1-37.

Ringuelet, R.A. 1961. Rasgos fundamentales de la zoogeografía de la Argentina. Physis 22 (63):151-170.

Río, M.E. y L. Achával 1905. Geografía de la Provincia de Córdoba. Vol. II. Compañía Sudamericana de Billetes de Banco, Buenos Aires.

Russell, N. 2012. Social Zooarchaeology: Humans and Animals in Prehistory. Cambridge University Press, Nueva York.

Shanks, M. y C.Y. Tilley 1987. Re-constructing Archaeology. Cambridge University Press, Cambridge.

Stahl, P.W. 1999. Structural density of domesticated South American camelid skeletal elements and the archaeological investigation of prehistoric Andean ch'arki. Journal of Archaeological Science 26 (11):1347-1368.

Tamburini, D.M. 2016. La Fauna Silvestre en las Estrategias de Reproducción Social de los Campesinos del Chaco Seco de la Provincia de Córdoba (Argentina). Tesis doctoral. Facultad de Ciencias Agropecuarias, Universidad Nacional de Córdoba, Córdoba.

Tamburini, D.M. y D. Cáceres 2017. Estrategias de uso de la fauna silvestre por las comunidades campesinas de Argentina Central. Etnobiología 15 (3):5-23.

Terán, B. (comp.) 2000. Lo que Cuentan los Tobas. Ediciones del Sol, Buenos Aires.

Torrella, S.A. y J. Adámoli 2005. Situación ambiental de la ecorregión del Chaco seco. En La Situación Ambiental Argentina, 
editado por A. Brown, U. Martínez Ortiz, M. Acerbi y J.F. Corcuera, pp. 75-82. Fundación Vida Silvestre Argentina, Buenos Aires.

Tuma, M.W. 2006. Ethnoarchaeology of subsistence behaviors within a rural African American community: Implications for interpreting vertebrate faunal data from slave quarters areas of antebellum plantation sites. Historical Archaeology 40 (4):1-26.

Villa, P. y E. Mahieu 1991. Breakage patterns of human long bones. Journal of Human Evolution 21 (1):27-48.

Wallach, A.D., M. Bekoff, C. Batavia, M.P. Nelson y D. Ramp 2018. Summoning compassion to address the challenges of conservation. Conservation Biology 32 (6):1255-1265.

Wallach, A.D., C. Batavia, M. Bekoff, S. Alexander, L. Baker, D. Ben-Ami, L. Boronyak, A.P.A. Cardilin, Y. Carmel, D. Celermajer, S. Coghlan, Y. Dahdal, J.J. Gomez, G. Kaplan, O. Keynan, A. Khalilieh, H. Kopnina, W.S. Lynn, Y. Narayanan, S. Riley, F.J. Santiago-Ávila, E. Yanco, M.A. Zemanova y D.
Ramp 2020. Recognizing animal personhood in compassionate conservation. Conservation Biology. doi:10.1111/cobi.13494.

Witmore, Ch. 2018. The end of the 'Neolithic'? At the emergence of the Anthropocene. En Multispecies Archaeology, editado por S. Birch, pp. 26-46. Routledge, Londres-Nueva York.

Yacobaccio, H.D., C.M. Madero y M.P. Malmierca 1998. Etnoarqueología de Pastores Surandinos. Grupo Zooarqueología de Camélidos, Buenos Aires.

Zak, M.R. y M. Cabido 2002. Spatial patterns of the Chaco vegetation of central Argentina: Integration of remote sensing and phytosociology. Applied Vegetation Science 5 (2):213-226.

Zak, M.R., M. Cabido, D. Cáceres y S. Díaz 2008. What drives accelerated land cover change in central Argentina? Synergistic consequences of climatic, socioeconomic, and technological factors. Environmental Management 42 (2):181-189.

\section{Notas}

1 Para más detalle, véase el debate en torno del artículo "En contra del populismo reaccionario: hacia una nueva arqueología pública", publicado en Chungara 51 (1).

2 Aunque también se realizaron dos entrevistas en Milagro, Departamento General Ocampo, La Rioja (Argentina) con personas que habían vivido en la región estudiada y hoy residen en la mencionada localidad.

3 En cuanto a las actividades de cacería en los obrajes, únicamente un entrevistado nos informó que los contratistas les abastecían de carne mientras trabajaban en ellos. Es importante aclarar que la persona trabajó hasta la década de 1970, mientras los demás actores lo hicieron en periodos posteriores.

$4 \quad$ P.ej.,: Legislación nacional: Ley $\mathrm{N}^{\circ} 22.421$, Decreto 666/97, Decreto 1290/00, Ley № 9.444 (arts. 105, 106 y 107); Legislación provincial: Ley 4.046, Decreto Ley 4.046/C/58, Ley 8.060, Resolución 137/2016, Resolución 138/2016, Resolución 4547/2016, Resolución 157/2019. Además, en los últimos años se crearon un parque nacional (P.N. Traslasierra) y una reserva arqueológica provincial (R.A.P. Guasapampa), hecho que podría generar mayor control sobre las actividades extractivas tradicionales y ocasionar más conflictos entre el Estado y la población local.

5 Nuestro objetivo a futuro es realizar excavaciones sistemáticas con el objeto de comprender mejor los procesos de formación del sitio.

6 Aunque algunas personas de la región han asociado esta cacería "dañina" a "gente de La Rioja, gente de Córdoba", utilizamos el término foráneo de una manera más amplia. Es decir, incluyendo a los lugareños que, según nuestra visión, han tenido que acomodarse a las "imposiciones" del Antropoceno y adquirieron una visión extractivista sobre el monte.

7 Según Descola (2001 [1996]:94), el naturalismo predatorio es una antigua práctica europea que adquiere su legitimación con la filosofía cartesiana y la mecanización del mundo. Con este comentario no pretendemos adjudicar una ontología particular a los campesinos de la región, únicamente creemos que algunas prácticas parecen obedecer a lógicas distintas a las del respeto al ambiente que los circunda (algo que aparece comúnmente en el discurso). Asimismo, remarcamos que muchas de las actividades en cuestión estaban regidas por una presión en ejecutar las órdenes de sus empleadores, que buscaban "optimizar su producción" incentivando a sus funcionarios a realizar un "control de plagas".

8 Este cambio también ha sido documentado en diversas comunidades indígenas de la región chaqueña (véase Arenas 2003; Manzano-García et al. 2019 o Terán 2000 para una reseña en el área de estudio). En este sentido, el mencionado desarraigo hace referencia a la falta de conexión con el entorno y/o atender a las expectativas extractivas de la economía de mercado.

9 Estos primeros acercamientos a los procesos y agentes tafonómicos en la región están siendo profundizados en el marco de la tesis doctoral de una de las autoras (MPW). De esta manera, a futuro podremos comprender mejor cómo ocurren estos fenómenos a nivel local.

10 Hemos realizado monitoreo de los agentes modificadores de carcasas de guanacos en el campo en cuestión. Resultados preliminares nos llevan a plantear esta hipótesis. podría incluir la nalga, palomita, cuadril, la bola de lomo, el bife angosto y el lomo (Instituto de Promoción de la Carne Vacuna Argentina, disponible en http://www.ipcva.com.ar/ vertext.php?id=1654).

12 Haciendo referencia a la recurrente confusión entre obtención de calorías y nutrientes con economía, es decir, la obtención y manejo de un recurso. Además, los animales son mucho más que un recurso, son seres que se relacionan a nivel individual y poblacional. También son mascotas, alimento y símbolos para los humanos, entre muchas otras cosas (véase Overton y Hamilakis 2013; Russell 2012). Sin embargo, en el Antropoceno muchos animales pasaron a ser considerados proto-carne (véase Witmore 2018:35).

13 Cabe destacar que algunos cazadores comentaron haber modificado su estrategia de cacería con perros, evitando alimentar a los cánidos domésticos con los órganos de las presas. Esta práctica se sustituyó dándoles a olfatear únicamente la orina como mecanismo de rastreo, consiguiendo de esta forma que los compañeros de caza se limiten a indicar la ubicación del animal perseguido y previniendo que lo destrocen una vez cazados (Manzano-García 2019).

14 De casa en casa ya que varias de las personas que hemos entrevistado afirman que "las patas" se prestan entre vecinos cuando las necesitan y las utilizan en los ámbitos domésticos (Manzano-García et al. 2019).
11 De acuerdo a los cortes vacunos en Argentina, esta porción 
15 Esto es evidente en las palabras de Jerónimo Luis de Cabrera, el fundador de la ciudad de Córdoba, en su descripción del territorio: "Hay grandes pastos y buenos asientos para poderse criar ganados en gran número de todos lo que en España se crían y hacer molinos y otras haciendas con que puedan vivir prósperos los que allí vivieren" (Relación en suma y de la tierra y poblaciones de Cabrera (1573, citado en Montes 2008:47).

16 Con algunas excepciones, generalmente asociadas a los carnívoros que predan el ganado. Dentro de ese listado, el puma es la especie que encabeza las valoraciones negativas desde la percepción local (Manzano-García 2019).

17 De acuerdo a www.iucnredlist.org/species/11186/18540211 visitado el 09/10/2019, el guanaco está categorizado de "baja preocupación", aunque el hecho no se aplica a las poblaciones chaqueñas. En esta línea, la situación del guanaco chaqueño ha sido reevaluada debido a que las poblaciones de la región se encuentran en estado crítico (Fernando Barri com. pers. 2019). Destacamos que venimos trabajando de manera transdisciplinar con los biólogos Fernando Barri y Lucila Castro (CONICET; NAEE) para conservar el guanaco en la región, y su declaración como patrimonio de la provincia se encuentra en trámite.

18 Son comunes los relatos que manifiestan recaudos al momento de cazar; en particular, relacionados a hembras preñadas de especies de menor porte (p.ej. Tolypeutes matacus). Estas son liberadas por los cazadores, que suelen capturarlas vivas con la ayuda de perros o con sus propias manos, al advertir su preñez dado que consideran que de esa manera se garantiza su continuidad en el tiempo.

19 En los términos previstos por la Convención para la Salvaguarda del Patrimonio Inmaterial realizada por la UNESCO: "Los usos, representaciones, expresiones, conocimientos y técnicas -junto con los instrumentos, objetos, artefactos y espacios culturales que les son inherentes- que las comunidades, los grupos y, en algunos casos, los individuos reconozcan como parte integrante de su patrimonio cultural, que se transmite de generación en generación, y es recreado constantemente por las comunidades y grupos en función de su entorno, su interacción con la naturaleza y su historia, infundiéndoles un sentimiento de identidad y continuidad y contribuyendo así a promover el respeto de la diversidad cultural y la creatividad humana en la Provincia de Córdoba". Disponible en http://web2.cba.gov.ar/web/leyes.nsf/85a69 a561f9ea43d03257234006a8594/c6579b128ecccad003257 c2b0053abc7?OpenDocument visitado el 28/11/2019.

20 Disponible en http://web2.cba.gov.ar/web/leyes.nsf/0/603 DCE7A084735F10325777C006CCE5F?OpenDocument\& Highlight=0,Caza,subsistencia, visitado el 28/11/2019.

21 Disponible en http://web2.cba.gov.ar/web/leyes.nsf/85a6 9a561f9ea43d03257234006a8594/0277fed6da7e3c61032 579f9006c19db? OpenDocument visitado el 28/11/2019. Evidentemente, esta ley no está pensada para la problemática de las comunidades rurales, ya que trata de la cacería deportiva y su retorno económico a la provincia.

22 Véase la interesante discusión acerca de la conservación compasiva en los trabajos de Wallach y colaboradores (2018, 2020) y en las críticas de Driscoll y Watson (2019).

23 Una primera discusión acerca de la propuesta se ha producido con representantes locales de la policía ambiental y responsables del área de arqueología de la Agencia Córdoba Cultura, durante el $1^{\circ}$ Encuentro de delegados ambientales para el cuidado del patrimonio: desafíos actuales y conjuntos en el territorio, llevado a cabo el 22 de noviembre de 2019 en la ciudad de Córdoba. 